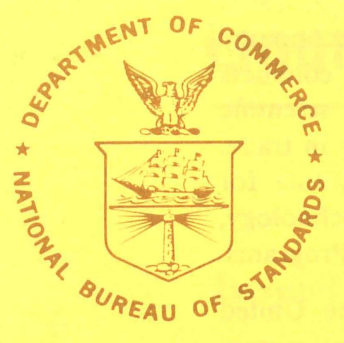

\title{
NBS MONOGRAPH 150
}

\section{U.S. DEPARTMENT OF COMMERCE / National Bureau of Standards}

\author{
$\sqrt[5]{5}[5] \sqrt[5]{5}]$ \\ APR $0>1976$ \\ DEPOSITORY \\ GOVERNMENT DOCUMENTS \\ UMKC LIBRARIES \\ Liquid-in-Glass Thermometry
}

LI INDA IHALL

LIBRAR

DOCUMENTS

APR 191976 


\section{NATIONAL BUREAU OF STANDARDS}

The National Bureau of Standards ${ }^{1}$ was established by an act of Congress March 3, 1901. The Bureau's overall goal is to strengthen and advance the Nation's science and technology and facilitate their effective application for public benefit. To this end, the Bureau conducts research and provides: (1) a basis for the Nation's physical measurement system, (2) scientific and technological services for industry and government, (3) a technical basis for equity in trade, and (4) technical services to promote public safety. The Bureau consists of the Institute for Basic Standards, the Institute for Materials Research, the Institute for Applied Technology, the Institute for Computer Sciences and Technology, and the Office for Information Programs.

THE INSTITUTE FOR BASIC STANDARDS provides the central basis within the United States of a complete and consistent system of physical measurement; coordinates that system with measurement systems of other nations; and furnishes essential services leading to accurate and uniform physical measurements throughout the Nation's scientific community, industry, and commerce. The Institute consists of the Office of Measurement Services, the Office of Radiation Measurement and the following Center and divisions:

Applied Mathematics - Electricity - Mechanics - Heat - Optical Physics - Center for Radiation Research: Nuclear Sciences; Applied Radiation - Laboratory Astrophysics ${ }^{2}$ - Cryogenics ${ }^{2}$ - Electromagnetics ${ }^{2}$ - Time and Frequency ${ }^{2}$.

THE INSTITUTE FOR MATERIALS RESEARCH conducts materials research leading to improved methods of measurement, standards, and data on the properties of well-characterized materials needed by industry, commerce, educational institutions, and Government; provides advisory and research services to other Government agencies; and develops, produces, and distributes standard reference materials. The Institute consists of the Office of Standard Reference Materials, the Office of Air and Water Measurement, and the following divisions:

Analytical Chemistry - Polymers - Metallurgy - Inorganic Materials - Reactor Radiation - Physical Chemistry.

THE INSTITUTE FOR APPLIED TECHNOLOGY provides technical services to promote the use of available technology and to facilitate technological innovation in industry and Government; cooperates with public and private organizations leading to the development of technological standards (including mandatory safety standards), codes and methods of test; and provides technical advice and services to Government agencies upon request. The Institute consists of the following divisions and Centers:

Standards Application and Analysis - Electronic Technology - Center for Consumer Product Technology: Product Systems Analysis; Product Engineering - Center for Building Technology: Structures, Materials, and Life Safety; Building Environment; Technical Evaluation and Application - Center for Fire Research: Fire Science; Fire Safety Engineering.

THE INSTITUTE FOR COMPUTER SCIENCES AND TECHNOLOGY conducts research and provides technical services designed to aid Government agencies in improving cost effectiveness in the conduct of their programs through the selection, acquisition, and effective utilization of automatic data processing equipment; and serves as the principal focus within the executive branch for the development of Federal standards for automatic data processing equipment, techniques, and computer languages. The Institute consists of the following divisions:

Computer Services - Systems and Software - Computer Systems Engineering - Information Technology.

THE OFFICE FOR INFORMATION PROGRAMS promotes optimum dissemination and accessibility of scientific information generated within NBS and other agencies of the Federal Government; promotes the development of the National Standard Reference Data System and a system of information analysis centers dealing with the broader aspects of the National Measurement System; provides appropriate services to ensure that the NBS staff has optimum accessibility to the scientific information of the world. The Office consists of the following organizational units:

Office of Standard Reference Data - Office of Information Activities - Office of Technical Publications - Library - Office of International Relations - Office of International Standards.

\footnotetext{
1 Headquarters and Laboratories at Gaithersburg, Maryland, unless otherwise noted; mailing address Washington, D.C. 20234.

${ }^{2}$ Located at Boulder, Colorado 80302.
} 
Jacquelyn A. Wise

Institute for Basic Standards

National Bureau of Standards

Washington, D.C. 20234

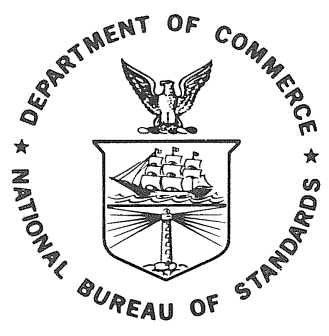

U.S. DEPARTMENT OF COMMERCE, Rogers C. B. Morłon, Secrełary James A. Baker, III, Under Secretary

Dr. Betsy Ancker-Johnson, Assistant Secretary for Science and Technology NATIONAL BUREAU OF STANDARDS, Ernest Ambler, Acting Director Issued January 1976 


\section{Library of Congress Cataloging in Publication Data}

Wise, Jacquelyn A.

Liquid-in-Glass Thermometry.

(NBS Monograph; 150)

Supersedes NBS monograph 90, Calibration of Liquid-in-Glass Thermometers, by J. F. Swindells.

Bibliography: p.

Supt. of Docs. No.: C13.44:150

1. Thermometers and Thermometery-Calibration. I. Swindells, James F. Calibration of Liquid-in-Glass Thermometers. II. Title. III. Series: United States. National Bureau of Standards. Monograph; 150.

QC100.U556 No. 150 [QC271.8.C3] 389'.08s [536'.51] 75-619230

\section{National Bureau of Standards Monograph 150}

Nat. Bur. Stand. (U.S.), Monogr. 150, 30 pages (Jan. 1976)

CODEN: NBSMA6

\section{U.S. GOVERNMENT PRINTING OFFICE WASHINGTON: 1976}

For sale by the Superintendent of Documents, U.S. Government Printing Office, Washington, D.C. 20402 (Order by SD Catalog No. C13.44:150). Price 85 cents. (Add 25 percent additional for other than U.S. mailing). 


\section{Contents}

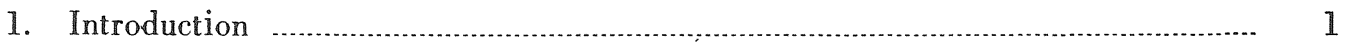

2. Thermometer Calibration Services at the NBS ….................................................. 1

2.1. Kinds of thermometers accepted for calibration .................................. 1

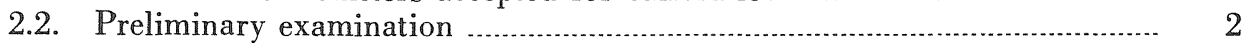

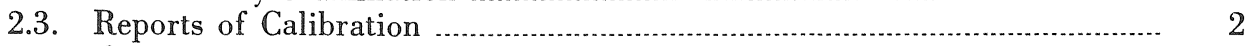

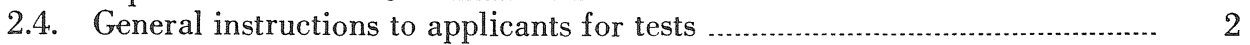

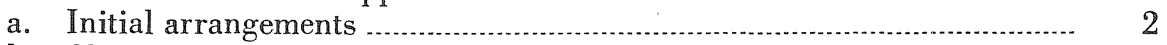

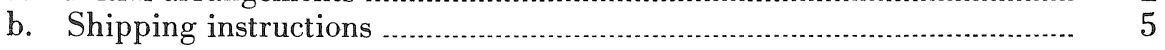

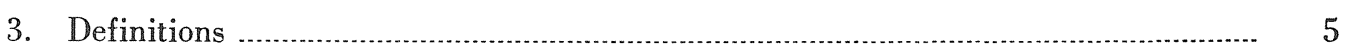

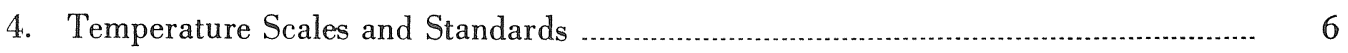

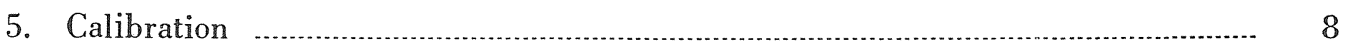

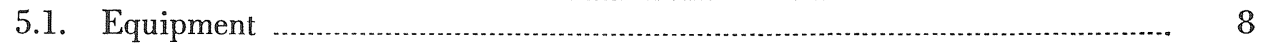

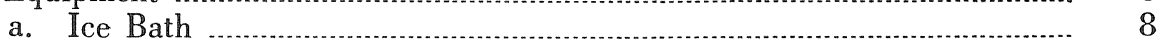

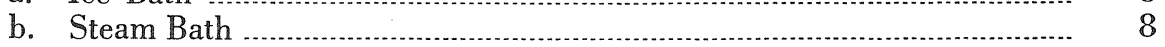

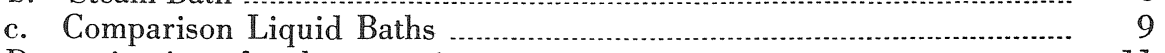

5.2. Determination of scale corrections ............................................................ 11

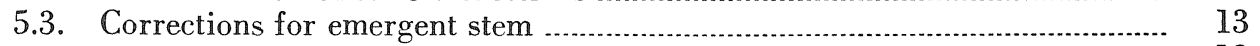

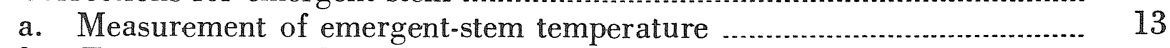

b. Formula for total-immersion thermometers .................................................. 14

c. Formula for partial-immersion thermometers ....................................... 15

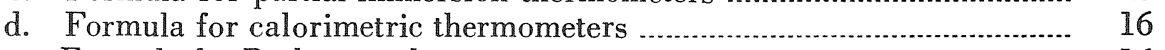

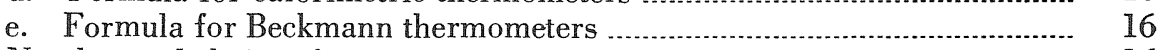

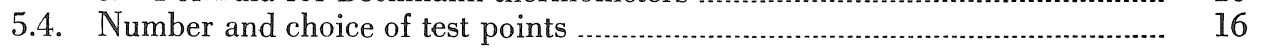

6. Common Thermometers and Factors Affecting Their Use ................................... 17

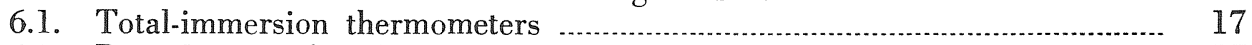

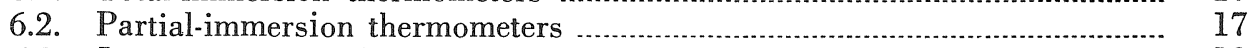

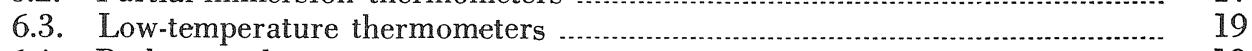

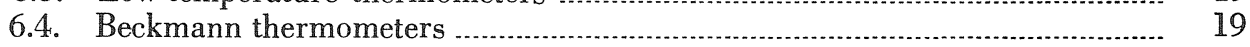

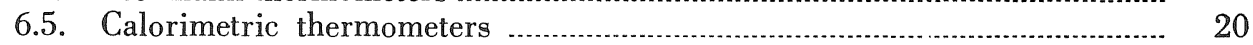

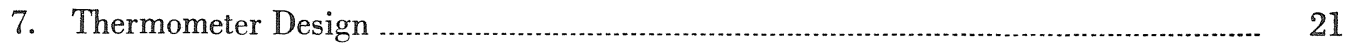

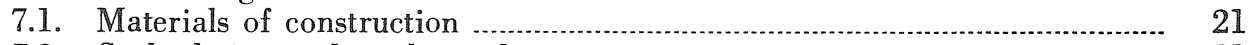

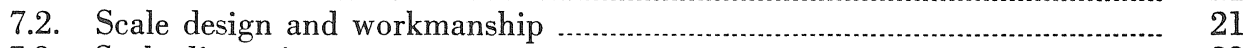

7.3. Scale dimensions ............................................................................... 22

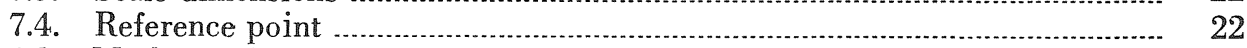

7.5. Marking of partial-immersion thermometers .......................................... 22

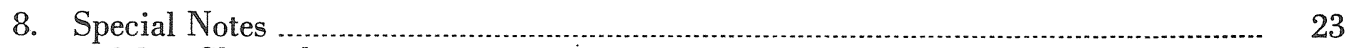

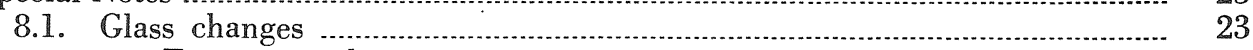

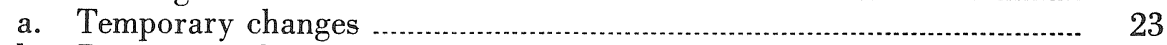

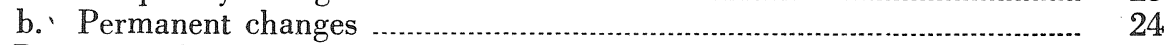

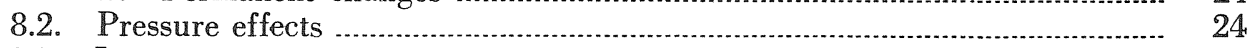

8.3. Lag ...

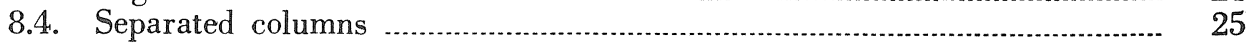

9. References .............................................................................................. 26 



\title{
Liquid-In-Glass Thermometry
}

\author{
Jacquelyn A. Wise
}

\begin{abstract}
This Monograph, which supersedes NBS Monograph 90, contains information of general interest to manufacturers and users of liquid-in-glass thermometers. Instructions explaining how to submit a thermometer to the National Bureau of Standards for calibration are provided, and the techniques and equipment, such as stirred liquid comparison baths, used in the calibration procedures are described. A discussion of important principles of acceptable thermometer design and factors affecting their use is included. Listed are tables of tolerances reflecting good manufacturing practices and reasonably attainable accuracies expected with liquid-in-glass thermometers. The calculation of corrections for the temperature of the emergent stem is given in detail for various types of thermometers and conditions of use.
\end{abstract}

Key words: Calibration; emergent stem; liquid-in-glass thermometer; reference point; stirred liquid comparison bath; temperature scale.

\section{Introduction}

It is the responsibility of the National Bureau of Standards (NBS) to accurately reproduce the International Practical Temperature Scale of $1968[1]^{1}$ as a basis for the uniform measurement of temperature throughout the scientific and industrial community of the United States. Because of this responsibility, NBS accepts for calibration with reference to this scale selected types of temperature-measuring instruments [2] for use as reference or working standards where precise temperature measurements are required. Certain liquid-in-glass thermometers are among the instruments accepted.
This Monograph is intended for those who may wish to submit thermometers for calibration or who desire information on the use of liquid-in-glass thermometers for precise temperature measurements. Practices employed at the NBS in the calibration of these thermometers are discussed. Also included is a brief discussion of the International Practical Temperature Scale of 1968, a description of the calibration equipment, and the accuracy capability of liquid-inglass thermometers. Details of good thermometer design and factors affecting their use are presented in a copious manner.

\section{Thermometer Calibration Services at the NBS}

The liquid-in-glass thermometer is one of many precision instruments calibrated by the NBS. A complete description of calibration services offered by the NBS appears in NBS Special Publication 250 [2], which can be obtained by writing to the Office of Technical Information and Publications, National Bureau of Standards, Washington, D. C. 20234. Supplements to NBS Special Publication 250 are issued periodically indicating any changes in these services.

\subsection{Kinds of Thermometers Accepted for Calibration}

Not all thermometers classified as liquid-in-glass are acceptable for calibration by the NBS. In general they must be of an acceptable design and workman-

${ }^{1}$ Figures in brackets indicate the literature references at the end of this Monograph. ship, and capable of being placed in the existing calibration facilities. The type known as laboratory or chemical thermometers, consisting of a solid stem with graduation lines and numbers permanently etched or placed on the stem, are regularly accepted. Others approved for calibration are Beckmann, calorimetric, and enclosed scale (Einschluss) laboratory thermometers. Industrial or mechanical type thermometers with special mountings can be accepted for test if they can be inserted in the comparison baths, or if the thermometer can be easily detached from the mounting.

Any thermometer, such as a household thermometer, consisting of a paper, plastic or metal mounting containing the scale graduations and attached to the unmarked glass thermometer by metal clips, is not acceptable for calibration. Maximum self-registering mercury-in-glass clinical thermometers are no longer tested at the NBS. 
It is advisable to contact the liquid-in-glass thermometry laboratory at NBS if there is any doubt concerning the acceptability of a thermometer for calibration. Every effort will be made to assist and satisfy the needs of the scientific and industrial community with problems involving temperature measurement.

\subsection{Preliminary Examination}

Every thermometer submitted for test must be uniquely identified by a serial number and pass a preliminary examination before final acceptance. These thermometers are viewed under a microscope having a magnification of 15 or $20 \mathrm{X}$ to assure that the mercury and capillary are clean. Any foreign matter found in the capillary or bulb that, in the judgment of the laboratory personnel, might tend to make the thermometer readings erratic, is reason for rejection.

Glass chips or oxides of mercury in the capillary or bulb are considered foreign matter that can cause the thermometer to indicate different readings at different periods of time. [For example, if a small chip of glass is located in the capillary at the $30^{\circ} \mathrm{C}$ indication, each time the mercury column advances past this point, it could cause the reading of the thermometer to vary for temperatures above $30^{\circ} \mathrm{C}$, because of different quantities of gas that may be trapped around the chip. The movement of the chip to different locations in the capillary, or the trapping of mercury around the chip when the mercury column recedes, would also cause erroneous readings.]

Other reasons a thermometer may be ineligible for test are given below:

(a) Defective design or workmanship.

(b) Part of graduated scale not usable.

(c) Errors in scale graduation or numbering.

(d) Unsuitable bulb glass or inadequate annealing.

(e) Inadequate gas filling.

(f) Cracks in the glass.

A complete list of all possible causes for rejection is not feasible. The prime consideration in the preliminary examination is that the thermometer be capable of precise, reproducible readings.

\subsection{Reports of Calibration}

In most instances a Report of Calibration will be issued by NBS for every liquid-in-glass thermometer submitted for test that is found free from serious defects as determined by the preliminary examination. In order to receive a Report of Calibration, the thermometer must be calibrated at two or more calibration points. If only one point is requested, a Report of Test will be issued.

The Report of Calibration contains the corrections determined for each point requested and an estimate of the uncertainties associated with the corrections. Also stated on the document are the agency or firm requesting the test, the trade mark and serial number on the thermometer, the NBS test number and completion date, and explanatory notes defining the conditions under which the results of the test are applicable. When necessary, accompanying the Report of Calibration is a sheel explaining how to calculate the corrections for emergent stem. If the thermometer is of the metastatic (Beckmann) type, the report will be accompanied by a second sheet containing a table of setting factors (See Sec. 6.4) enabling the user to apply the calibration results for settings other than the $20^{\circ} \mathrm{C}$ setting for which the corrections are reported. A facsimile of a Report of Calibration is shown in figures 1 and 2 .

Any departure from the conditions under which the corrections were obtained, as stated on the Report of Calibration, may significantly change the values of the corrections. Conditions of immersion are particularly important (Sec. 6). It should be emphasized that the estimates of error assigned to the scale corrections do not assure the user of this accuracy in a temperature measurement.

\subsection{General Instructions to Applicants for Tests}

Testing will be conducted in accordance with the policies of NBS as described in NBS Special Publication 250. The cost of calibration will depend on the number of calibration points requested, the temperature range, and the quantity of thermometers submitted. For tests not specifically outlined in the above publication, NBS should be consulted. If the required measurements appear feasible, and, in the opinion of NBS, sufficiently important to justify the work, such tests will be undertaken for a special fee determined by the nature of the work and time involved. In all requests for test the following procedures and information are pertinent.

\section{a. Initial Arrangements}

A letter or purchase order requesting the test must be sent to NBS either with the thermometer or separately. No work can be undertaken unless both the thermometer and letter or purchase order have been received. Information in the request for test should include the quantity and serial numbers of the thermometers sent, the calibration points required, (See Sec. 5.4) and the suggested method for return shipment. If it is desired that the thermometer be insured upon return, a statement to this effect must appear on the request, and a value assigned; otherwise, the thermometer will be returned uninsured.

NBS will assign a test number to each calibration request and acknowledge the receipt of the thermometer. On the acknowledgment will be stated the estimated completion date and estimated cost of calibration. Any foreseeable difficulty that may be encountered involving the calibration will be mentioned on the acknowledgment, as well as the name of someone in the testing laboratory who can be contacted if questions arise. 


\section{U.S. DEPARTMENT OF COMMERCE \\ NATIONAL BUREAU OF STANDARDS \\ INSTITUTE FOR BASIC STANDARDS \\ WASHINGTON, D.C. 20234 \\ RE P OR T O F C A L I B R A T I O N \\ LIQUID-IN-GLASS THERMOMETER}

TESTED FOR: NATIONAL BUREAU OF STANDARDS

DIVISION 221, SECTION 11

MARKED: SURETY 198692

RANGE: -2 TO +102 DEGREES C IN 0.2 DEGREE

$\begin{array}{rc}\text { THERMOMETER } & \text { CORRECTION } \\ \text { READING } & \text { (IPTS-68) } \\ -.06 \text { C } & .06 \mathrm{C} \\ 20.00 & .13 \\ 40.00 & .05 \\ 60.00 & .04 \\ 80.00 & .06 \\ 100.00 & .04\end{array}$

*ALL TEMPERATURES IN THIS RFPOFT ARE BASED ON THE INTERNATIONAL

PRACTICAL TEMPERATURE SCALE OF 1968, IPTS-68. THIS TEMPERATURE SCALE

WAS ADOPTED BY THE INTERNATIONAL COMMITTEE OF WEIGHTS AND MEASURES AT ITS MEETING IN OCTOBER, 1968, AND IS DESCRIBED IN "THE INTERNATIONAL PFACTICAL TEMPERATURE SCALE OF 1968," METROLOGIA, VOL.5, NO,2, 35 (APRIL 1969).

ESTIMATED UNCERTAINTIES IN THE ABOVE CORRECTIONS DO NOT EXCEED 0.05 DEGREE UP TO 102 DEGREES C.

FOR A DISCUSSION OF ACCURACIES ATTAINABLE WITH SUCH THERMOMETERS SEE NATIONAL BUREAU OF STANDARDS MONOGRAPH 150, LIQUIO-IN-TLLASS

THERMOMETRY.

IF NO SIGN IS GIVEN ON THE CORRECTION, THE TRUE TEMPERATURE IS HIGHER THAN THE INDICATED TEMPERATURE: IF THE SIGN GIVEN IS NEGATIVE, THE TRUE TEMPFRATURE IS LOWER THAN THE INOICATED TEMPERATURE. TO USE THE CORRECTIONS PFOPERLY, REFERENCE SHOULD BE MADE TO THE NOTES GIVEN BELOW.

THE TABULATED CORRECTIONS APPLY FOR THE CONDITION OF TOTAL IMMERSION OF THE BULB AND LIQUID COLUMN. IF THE THERMOMETER IS USED AT PARTIAL IMMERSIUN, APPLY AN EMERGENT STEM CORRECTION AS EXPLAINED IN THE ACCOMPANYING STEM CORRECTION SHEET.

TEST NUMBER $311-11-74$

COMPLETED $5-9-74$

Figure 1. Facsimile of page 1 of a Report of Calibration. 
THE TABULATED CORRECTIONS APPLY PROVIDED THE ICE-POINT READING, TAKEN AFTER EXPOSURE FOR NOT LESS THAN 3 DAYS TO A TEMPERATURE OF ABOUT 23 DEGREES C $(73$ DEGREES F), IS $-0.06 \mathrm{C}$. IF THE ICE-POINT READING IS FOUND TO BE HIGHER (OR LOWER) THAN STATED, ALL OTHER READINGS WILL BE HIGHER (OR LOWER) BY THE SAME AMOUNT. IF THE THERMOMETER. IS USED AT A GIVEN TEMPERATURE SHORTLY AFTER BEING HEATED TO A HIGHER TEMPERATURE, AN ERROR OF 0.01 DEGREE OR LESS, FOR EACH 10-DEGREE UIFFERENCE BETWEEN THE TWO TEMPERATURES, MAY BF INTRODUCED. THE TABULATED CORRECTIONS APPLY IF THE THERMOMETER IS USED IN ITS UPRIGHT POSITION: IF USED IN A HORIZONTAL POSITION. THE INDICATIIONS MAY BE A FEW HUNDREDTHS OF A DEGREE HIGHER.

TEST NUMBER $311-11-74$ FOR THE DIRECTOR, COMPLETED 5-9-74

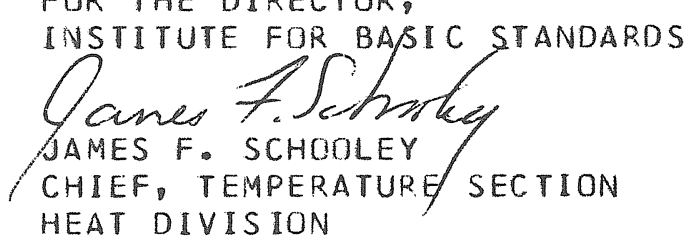




\section{b. Shipping Instructions}

To assure safe arrival of the thermometers, they should be packed firmly in their individual cases. A rigid material, such as wooden slats or corrugated paper, can be wrapped around the thermometer case as an additional aid against breakage. The package should contain enough packing material to absorb any shock that it may receive. Included with each shipment should be a packing list stating the number of thermometers shipped, the name of the company sub- mitting them, and, if applicable, the company's purchase order number.

Unless otherwise specified, the thermometers will be returned via the best method in the judgment of NBS. Shipping charges, both to and from the NBS, will be paid by the applicant. All possible care will be taken in handling thermometers at NBS, but the risk of damage either in shipment or testing must be assumed by the agency, firm or individual submitting them.

\section{Definitions}

The principle features of a solid-stem liquid-in-glass thermometer are shown in figure 3 . Not all of the features shown would necessarily be incorporated in any one thermometer.

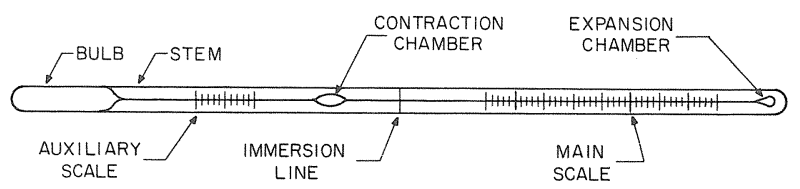

Figure 3. Principle features of a solid-stem liquid-in-glass thermometer.

Bulb: The reservoir for the thermometer liquid. The bulb of a thermometer will contain a volume equivalent to a specific number of degrees of the scale depending upon the coefficients of expansion of the thermometric liquid and bulb glass. For mercury in a bulb made of "normal" glass, the bulb volume is equivalent to approximately 6,222 times the volume of a 1 degree length of the capillary on the scale for Celsius thermometers, or 11,200 times the volume of a 1 degree length of the capillary on the scale for Fahrenheit thermometers. For organic thermometric liquids with higher coefficients of expansion than mercury, the bulb volumes are correspondingly less.

Stem: The glass capillary tube through which the thermometric liquid advances or retreats with changes in temperature.

Main Scale: The scale graduated in degrees or multiples or submultiples of degrees; in many instances the main scale constitutes the only scale.

Auxiliary Scale: A short scale including a reference temperature such as the ice point, to provide a means for checking the thermometer for a change in calibration with time (see Sec. 7.4). This scale is added when a suitable reference temperature is not included in the range of the main scale.

Expansion Chamber: An enlargement at the top end of the capillary bore having a volume equivalent to not less than the volume of a $20 \mathrm{~mm}$ length of unchanged capillary. Smaller chambers are not regarded as expansion chambers. The expansion chamber is provided to prevent the buildup of excessive pressures in gas-filled thermometers as the liquid filling advances toward the top of the scale (see Sec. 7.1).

Contraction Chamber: An enlargement of the capillary bore which serves to reduce a long length of capillary or to prevent contraction of the entire liquid column into the bulb. This chamber is introduced below the main scale or between the main scale and an auxiliary scale.

Reference Point: A reference temperature, such as the ice point or steam point, used periodically to check the thermometer for changes in bulb volume. (See Sec. 5.2). The reference point can be included in the main scale or on an auxiliary scale.

Total-Immersion Thermometer: A thermometer designed to indicate temperatures correctly when the bulb and the entire liquid column is exposed to the temperature being measured. (See the definition for complete-immersion thermometer.)

Partial-Immersion Thermometer: A thermometer designed to indicate temperatures correctly when the bulb and a specified portion of the stem is exposed to the temperature being measured. The remaining portion of the stem, referred to as the emergent stem, will be at the ambient temperature, usually different from the temperature being measured. Such thermometers are generally marked with an immersion line to indicate the proper depth of immersion.

Complete-Immersion Thermometer: A thermometer designed to indicate temperatures correctly when the whole thermometer, including the expansion chamber, is subjected to the temperature being measured. In gasfilled thermometers the reading will be different for complete, as compared to total immersion, as a result of the effect of temperature on the gas pressure in the thermometer (see Sec. 8.2). Although the difference in readings under the two conditions is particularly significant at high temperatures, it is also significant at moderate temperatures if the bulb and expansion chamber are both relatively large.

Calibration Points: The temperatures on the thermometer scale (i.e., $0^{\circ} \mathrm{C}$ ) where calibrations are performed and corrections reported. 
Accuracy: The accuracy of a measurement refers to the difference between the measured value and the true value of the quantity being measured. In this Monograph the accuracy of a given thermometer refers to its ability to indicate temperatures correctly on the International Practical Temperature Scale of 1968 [1] within the uncertainty stated (See tables 5-12) provided all corrections are applied and the thermometer is used in the same manner as when it was calibrated. The accuracy attainable is principally limited by the characteristics of the thermometer itself (See Sec. 6).
Instability of the thermometer glass, capillary forces at the surface of the thermometric liquid, nonuniformity of capillary bore, and inaccuracies in scale graduation are among the important factors. With partial-immersion thermometers, uncertainties in corrections for the emergent stem may greatly limit the accuracy. Observer errors are also involved, but with care these can usually be made relatively small.

Precision: The precision of measurement refers to the degree of agreement amongst repeated measurements at a given time of the same quantity.

\section{Temperature Scales and Standards}

The scale to which measurements of temperature should ultimately be referred is the Thermodynamic Kelvin Temperature Scale (TKTS). Values of temperature expressed on the TKTS are designated by the symbol $T$. The unit of temperature is the Kelvin, symbol K, which is a base unit of the Systeme Internationale (SI), and is defined as "the fraction $1 / 273.16$ of the thermodynamic temperature of the triple point of water" [3].

Because of the difficulties that are encountered in the practical realization of the TKTS, it has been necessary to define and utilize practical temperature scales. The International Temperature Scale and defining text was first adopted in 1927 and later revised in 1948. The Eleventh General Conference of Weights and Measures in 1960 changed the name of the scale to the International Practical Temperature Scale (IPTS) of 1948 and adopted a revised text of the scale [4], although numerically the scale was not changed. In 1968, in accordance with the power given to it by Resolution 8 of the Thirteenth General Conference of Weights and Measures, the International Committee of Weights and Measures adopted the International Practical Temperature Scale of 1968 [1], henceforth referred to as IPTS-68. The IPTS-68 replaced the International Practical Temperature Scale of 1948 and may be expressed either as a Kelvin scale or as a Celsius scale.

The present Celsius scale has its zero $0.01 \mathrm{~K}$ below the triple point of water (essentially the ice point). The value of a temperature expressed on the Thermodynamic Celsius Temperature Scale is designated by the symbol $t$ and is related to the value on the TKTS by

$$
t=T-273.15 \mathrm{~K} \text {. }
$$

The unit of the Celsius Scale is the degree Celsius, symbol ${ }^{\circ} \mathrm{C}$, which by definition is equal in magnitude to the Kelvin.

Values of temperature expressed on the International Practical Kelvin Scale are designated by the symbol $T_{68}$, and values of temperatures expressed on the International Practical Celsius Temperature Scale are designated by the symbol $t_{68}$. The relationship between $T_{68}$ and $t_{68}$ is

$$
t_{68}=T_{68}-273.15 \mathrm{~K} \text {. }
$$

The units of $T_{68}$ and $t_{68}$, like the thermodynamic scales, are the Kelvin, symbol $\mathrm{K}$, and degree Celsius, symbol ${ }^{\circ} \mathrm{C}$.

Due to the use of more sophisticated equipment and the ability to measure with more accuracy the defining fixed points, the new temperature scale more closely agrees with thermodynamic temperatures. This scale, IPTS-68, is intended to provide scientific and industrial laboratories throughout the world with a common basis for stating temperatures. Calibrations of thermometers at NBS, therefore, are made with reference to values of temperature on the IPTS-68.

Shown in Table 1 is the approximate difference in degrees Celsius between the values of temperature given by the IPTS-68 and the IPTS-48 [1]. The differences are listed in two separate sections for convenience and clarity. It can be seen, by studying these values, that the correction is important if quality control in the laboratory is to be maintained to the nearest $0.01{ }^{\circ} \mathrm{C}$. If, on the other hand, accuracies no better than the nearest $0.1^{\circ} \mathrm{C}$ are desired, the correction becomes less significant in the liquid-in-glass thermometer region $\left(-200\right.$ to $\left.+600{ }^{\circ} \mathrm{C}\right)$ of temperature measurements.

Although values of temperatures on the IPTS-68 are expressed in degrees Celsius, thermometers that are graduated on the Fahrenheit Scale can be calibrated with reference to the IPTS.68 by using the conversion formula:

$$
\begin{gathered}
\text { temperature value in }{ }^{\circ} \mathrm{F}=9 / 5 \\
\left(\text { temperature value in }{ }^{\circ} \mathrm{C}\right)+32
\end{gathered}
$$

The National Bureau of Standards has been performing calibrations with reference to the IPTS-68 since July, 1969. On all Reports of Calibration and Reports of Test issued after this date, it has been clearly indicated that the new scale was used.

In the range of temperatures normally covered by liquid-in-glass thermometry, the IPTS-68 is defined by four fixed points: the equilibrium between the liquid and vapor phases of oxygen (normal boiling point of oxygen) at $-182.962{ }^{\circ} \mathrm{C}$; the equilibrium between solid, liquid, and vapor phases of water (triple point of water) at $+0.01{ }^{\circ} \mathrm{C}$; the equilibrium between the liquid and vapor phases of water (nor- 
TABle 1. - Approximate difference $\left(i_{68}-t_{48}\right)$, in degrees Celsius,

between the values of temperature given by the IPTS-68 and IPTS-48

\begin{tabular}{|c|c|c|c|c|c|c|c|c|c|c|c|}
\hline \multicolumn{6}{|c|}{ 1a. For the range } & \multicolumn{6}{|c|}{$-180^{\circ} \mathrm{C}$ to $0^{\circ} \mathrm{C}$. } \\
\hline$t_{68}{ }^{\circ} \mathrm{C}$ & 0 & -10 & -20 & -30 & -40 & -50 & -60 & -70 & -80 & -90 & -100 \\
\hline $\begin{array}{r}-100 \\
-\quad 0\end{array}$ & $\begin{array}{l}0.022 \\
0.000\end{array}$ & $\begin{array}{l}0.013 \\
0.006\end{array}$ & $\begin{array}{l}0.003 \\
0.012\end{array}$ & $\begin{array}{r}-0.006 \\
0.018\end{array}$ & $\begin{array}{r}-0.013 \\
0.024\end{array}$ & $\begin{array}{r}-0.013 \\
0.029\end{array}$ & $\begin{array}{r}-0.005 \\
0.032\end{array}$ & $\begin{array}{l}0.007 \\
0.034\end{array}$ & $\begin{array}{l}0.012 \\
0.033\end{array}$ & 0.029 & 0.022 \\
\hline \multicolumn{12}{|c|}{ lb. For the range $0^{\circ} \mathrm{C}$ to $1070^{\circ} \mathrm{C}$. } \\
\hline$t_{68}^{\circ}{ }^{\circ} \mathrm{C}$ & 0 & 10 & 20 & 30 & 40 & 50 & 60 & 70 & 80 & 90 & 100 \\
\hline $\begin{array}{r}0 \\
100 \\
200 \\
300 \\
400 \\
500 \\
600 \\
700 \\
800 \\
900 \\
1000\end{array}$ & $\begin{array}{l}0.000 \\
0.000 \\
0.043 \\
0.073 \\
0.076 \\
0.079 \\
0.150 \\
0.39 \\
0.67 \\
0.95 \\
1.24\end{array}$ & $\begin{array}{c}-0.004 \\
0.004 \\
0.047 \\
0.074 \\
0.075 \\
0.082 \\
0.165 \\
0.42 \\
0.70 \\
0.98 \\
1.27\end{array}$ & $\begin{array}{l}-0.007 \\
0.007 \\
0.051 \\
0.075 \\
0.075 \\
0.085 \\
0.182 \\
0.45 \\
0.72 \\
1.01 \\
1.30\end{array}$ & $\begin{array}{c}-0.009 \\
0.012 \\
0.054 \\
0.076 \\
0.075 \\
0.089 \\
0.200 \\
0.47 \\
0.75 \\
1.04 \\
1.33\end{array}$ & $\begin{array}{c}-0.010 \\
0.016 \\
0.058 \\
0.077 \\
0.074 \\
0.094 \\
0.23 \\
0.50 \\
0.78 \\
1.07 \\
1.36\end{array}$ & $\begin{array}{c}-0.010 \\
0.020 \\
0.061 \\
0.077 \\
0.074 \\
0.100 \\
0.25 \\
0.53 \\
0.81 \\
1.10 \\
1.39\end{array}$ & $\begin{array}{c}-0.010 \\
0.025 \\
0.064 \\
0.077 \\
0.074 \\
0.108 \\
0.28 \\
0.56 \\
0.84 \\
1.12 \\
1.42\end{array}$ & $\begin{array}{c}-0.008 \\
0.029 \\
0.067 \\
0.077 \\
0.075 \\
0.116 \\
0.31 \\
0.58 \\
0.87 \\
1.15 \\
1.44\end{array}$ & $\begin{array}{c}-0.006 \\
0.034 \\
0.069 \\
0.077 \\
0.076 \\
0.126 \\
0.34 \\
0.61 \\
0.89 \\
1.18\end{array}$ & $\begin{array}{c}-0.003 \\
0.038 \\
0.071 \\
0.076 \\
0.077 \\
0.137 \\
0.36 \\
0.64 \\
0.92 \\
1.21\end{array}$ & $\begin{array}{l}0.000 \\
0.043 \\
0.073 \\
0.076 \\
0.079 \\
0.150 \\
0.39 \\
0.67 \\
0.95 \\
1.24\end{array}$ \\
\hline
\end{tabular}

Examples showing the use of these tables are given below to help clarify any difficulty that may be encountered.

I Standard thermometer reading

Correction from NBS Report of Calibration

True temperature IPTS-48

Correction from the above table at $-36.50^{\circ} \mathrm{C}$

True temperature IPTS-68

II Standard thermometer reading

Correction from NBS Report of Calibration

True temperature IPTS-48

Converted correction from the above tables*

True temperature IPTS-68

$$
\begin{aligned}
& -36.56{ }^{\circ} \mathrm{C} \\
& +\quad .06 \\
& \hline-36.50{ }^{\circ} \mathrm{C} \\
& +\quad .02 \\
& \hline-36.48{ }^{\circ} \mathrm{C} \\
& -98.32{ }^{\circ} \mathrm{F} \\
& -\quad .02 \\
& \hline-98.30{ }^{\circ} \mathrm{F} \\
& -\quad .02 \\
& \hline 98.28^{\circ} \mathrm{F}
\end{aligned}
$$

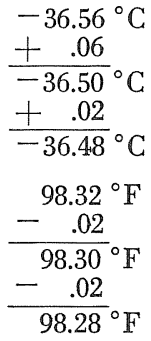

*The converted correction is obtained by:

A. Convert the Fahrenheit temperature to Celsius $98.30{ }^{\circ} \mathrm{F}=36.83^{\circ} \mathrm{C}$.

B. Find the correction from the table at $36.83{ }^{\circ} \mathrm{C}$. It is $-0.01{ }^{\circ} \mathrm{C}$.

C. Convert this correction to Fahrenheit by multiplying by $9 / 5$.

$-0.01{ }^{\circ} \mathrm{C} \times 9 / 5 \approx-0.02{ }^{\circ} \mathrm{F}$.

mal boiling point of water) at $100{ }^{\circ} \mathrm{C}$; and the equilibrium between solid and liquid phases of zinc (freezing point of zinc) at $419.58^{\circ} \mathrm{C}$. Temperatures in the range -182.96 to $630.7{ }^{\circ} \mathrm{C}$ are defined in terms of a standard platinum resistance thermometer that has been calibrated at the four fixed points, with interpolations and extrapolations between and beyond these points accomplished by employing specified equations [1].

When the highest accuracy is required in a calibration, the thermometer indications are compared directly with temperatures obtained using a standard platinum resistance thermometer. At NBS all calibrations are performed in this manner, with the exception of the ice point (See Sec. 5.2). If a lower accuracy is required, one of several mercury-in-glass thermometers with ranges and graduated in the intervals listed be- low may be used as standards for total-immersion comparisons.

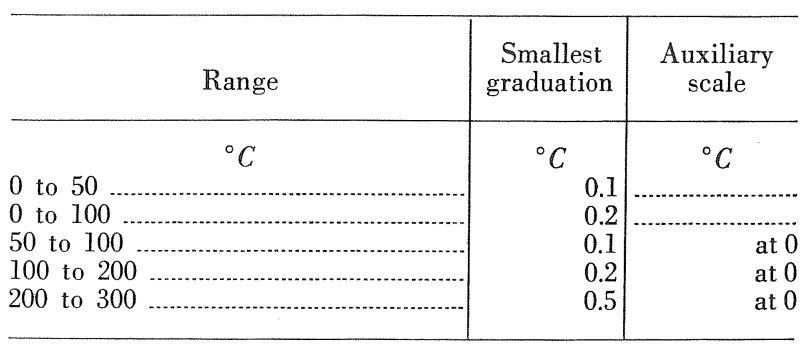

Partial-immersion thermometers, known as "like standards," can be maintained for the calibration of thermometers manufactured to similar specifications. 
These standards are calibrated for stem-temperature conditions expected to prevail during the use of these thermometers or for specified stem temperatures. This use of like standards eliminates the need for many of the precautions necessary when dissimilar thermometers are compared and permits the direct comparison of the indications of similar thermometers as long as the bulbs are at the same temperature and the stem temperatures are essentially the same for all of the thermometers under comparison.

All of these liquid-in-glass standards should be calibrated with reference to the IPTS-68 through comparisons with a standard platinum resistance thermometer.

\section{Calibration}

In most instances, the determination of the liquidin-glass thermometer scale corrections is accomplished by comparing its scale indications with a known temperature from a platinum resistance thermometer or mercury-in-glass thermometer standards. This comparison is achieved by placing the standard and the thermometers under test in a series of stirred liquid comparison baths (See Sec. 5.1c). A discussion of the equipment needed, the procedure followed, additional corrections that may be necessary, and the choice of calibration points is given in the following sections.

\subsection{Equipment}

\section{a. Ice Bath}

An ice bath can be easily assembled and consists of a container, a siphon tube, ice and distilled water. A Dewar flask, approximately $36 \mathrm{~cm}$ deep and $8 \mathrm{~cm}$ in diameter, can serve as a container for the ice. A vessel of this type is preferable, since the melting of the ice is retarded by the insulating properties of the Dewar flask. A siphon is placed in the flask to enable excess water to be removed as the ice melts. The clear or transparent portion of commercially purchased ice, or ice made from distilled water, can be used. The ice is shaved or crushed into small chips measuring 2 to $5 \mathrm{~mm}$. The flask is one-third filled with distilled water and the shaved ice is added. This mixture is compressed to form a tightly packed slush and any excess water is siphoned off. Before the bath is used, adequate time ( 15 to $30 \mathrm{~min}$.) should be given for the mixture to reach a constant temperature throughout.

Ideally there should be as much ice in the flask as possible, with the small spaces between the chips filled with distilled water. It will be necessary periodically to add ice and to remove the excess water while the bath is being used to maintain this ideal consistency. If care is taken to prevent contamination of the ice and water, the ice point can be realized to better than $0.01{ }^{\circ} \mathrm{C}$ by this means.

\section{b. Steam Bath}

A schematic drawing of a steam bath is shown in figure 4. Steam produced from the boiler circulates within a double-walled steam jacket permitting free circulation of steam around the thermometers suspended within this space. A provision is made both for relieving any excess pressure in the space surrounding the thermometers and for determining the excess pressure by means of a small differential manometer.

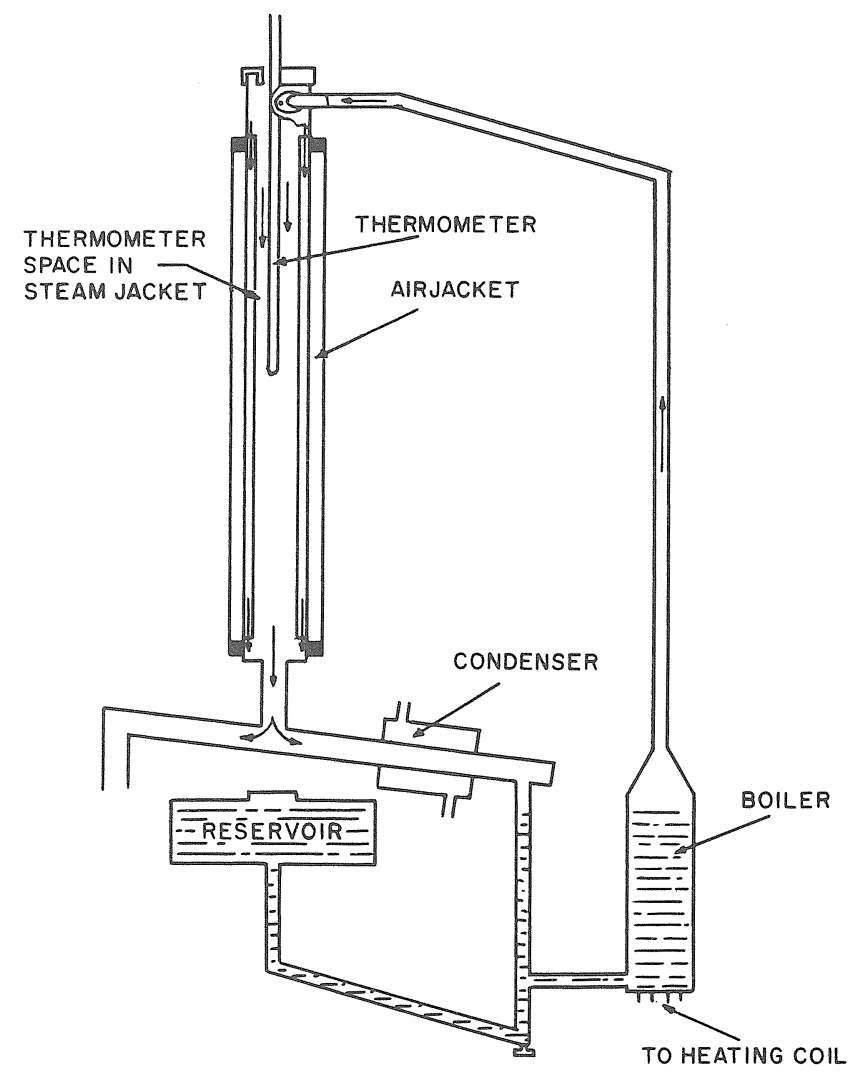

Figure 4. Schematic drawing of steam bath.

When the steam bath is used as a fixed-point apparatus, a barometer is a necessary accessory, since the temperature of the steam depends upon the prevailing atmospheric pressure. The usual adjustments are made to the barometer reading, including any necessary corrections for the value of local acceleration of gravity, for the difference in height between 
the steam bath and the barometer, and for any excess pressure above atmospheric in the steam jacket. After the corrected pressure reading is obtained, the temperature of the steam can be derived from the values given in Table 2. With a barometer accurate to 0.1 $\mathrm{mm} \mathrm{Hg}$, this procedure is capable of an accuracy of 0.002 to $0.003{ }^{\circ} \mathrm{C}\left(0.004\right.$ to $\left.0.005^{\circ} \mathrm{F}\right)$. The Fortin type barometer will usually suffice for all but the most exacting measurements.

The steam bath can also be used as a comparison bath, with the temperature of the steam being determined at the time of test by means of a previously standardized thermometer. This method, which does not require the use of a barometer, may be preferable, particularly when a platinum resistance thermometer can be used as the standard.

\section{c. Comparison Liquid Baths}

At NBS two types of stirred liquid baths are used for comparison calibrations in the range -110 to $540{ }^{\circ} \mathrm{C}$ ( -166 to $\left.1004{ }^{\circ} \mathrm{F}\right)$. Each is equipped with a stirring unit to provide a uniform temperature throughout the medium and a controlled current to the heating coils for proper temperature regulation. A 5 to $7 \mathrm{~cm}$ thickness of insulation surrounding the baths and an insulated cover is provided to help minimize heat loss. Fitted into the top cover is a holder containing the thermometers. This holder can be rotated, enabling each thermometer to appear in the field of view of a vertically adjustable telescope attached to each bath.

TABLE 2. - (Thermometric) condensation temperature of steam [5]

[Asterisk (*) indicates change in integer]

Pressure in mm mercury (standard)

\begin{tabular}{llllllllllll}
\hline $\mathrm{P}$ & 0 & 1 & 2 & 3 & 4 & 5 & 7 & 8 & 7 \\
\hline
\end{tabular}

Temperature in degrees of International Practical Temperature Scale of 1968

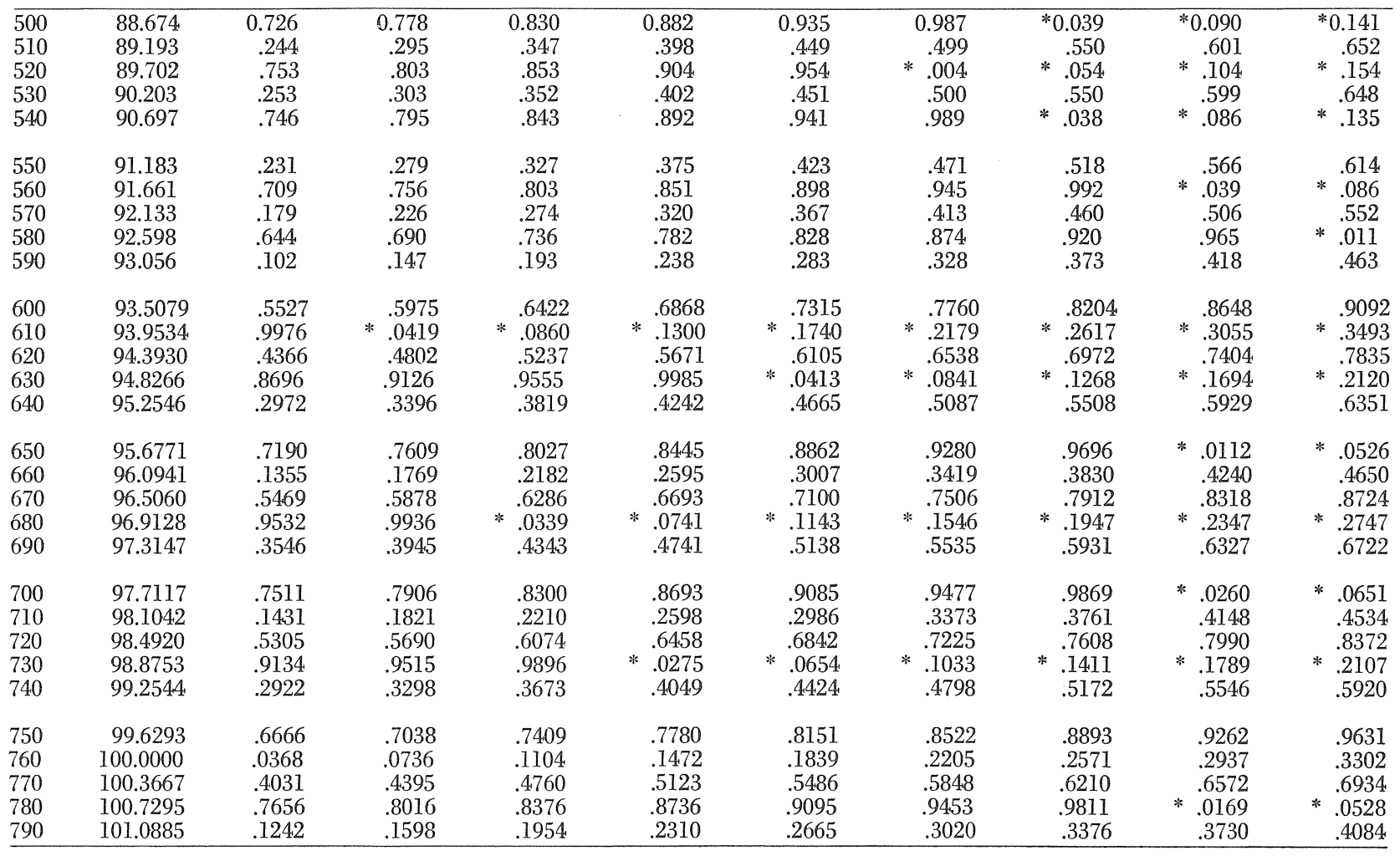


The type of bath shown in figure 5 is suitable when the medium is liquid at room temperature. It consists of two cylindrical wells of different diameters with connecting passages at the top and bottom. The heating coil and stirrer are located in the smaller well, leaving the larger well unobstructed for the insertion of the thermometers. The fluid is forced past the heating coils, through the bottom opening into the larger well, around the thermometers, and back into the smaller well through the connecting passage at the top.

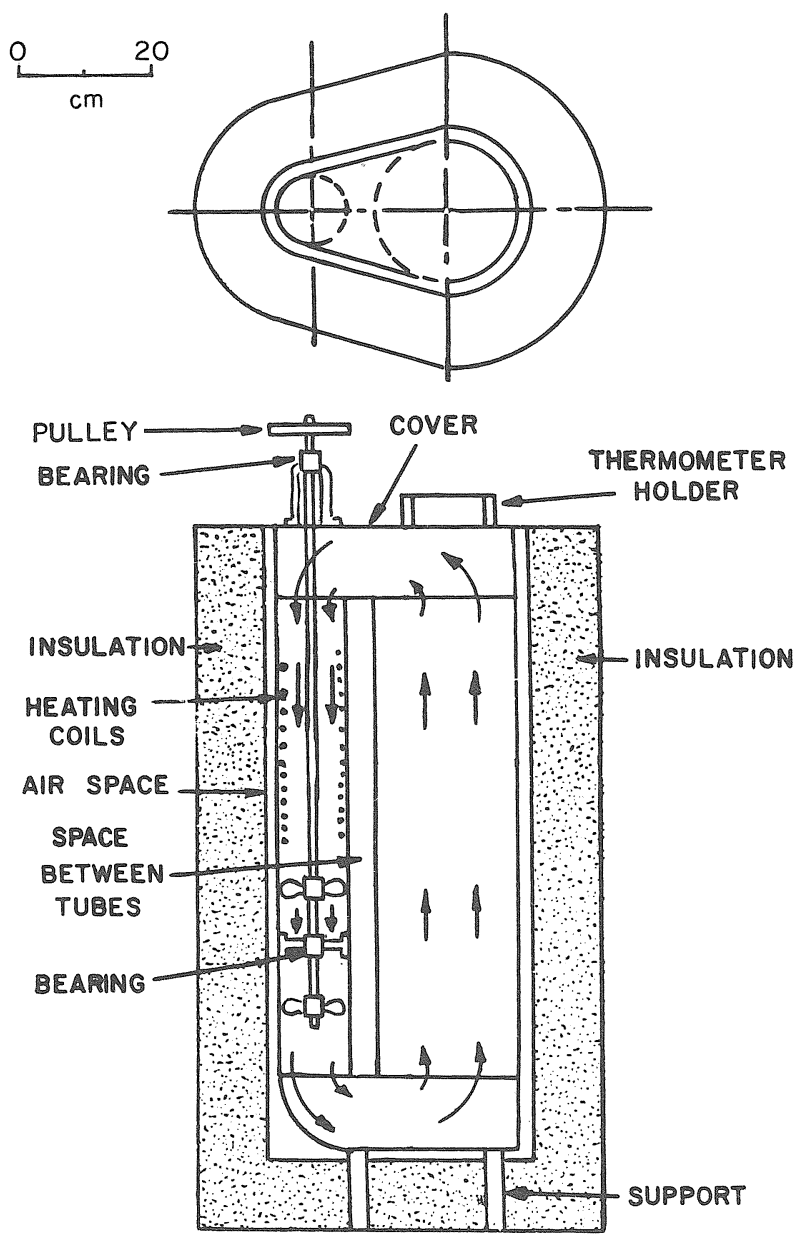

Figure 5. Stirred liquid bath.

The bath illustrated in figure 6 is designed for use with a medium that is solid at room temperature. A bath of this type is used at NBS for high temperature calibrations. Two coaxial cylinders are arranged in such a way as to permit the medium to circulate between the walls of the two cylinders and through the inner cylinder by means of openings at the top and bottom. The stirring propeller is situated near the bottom of the inner cylinder, leaving the majority of the space for the reentrant tubes into which the thermometers are inserted. The heater coils are wound on the outside of the outer cylinder. Both types of
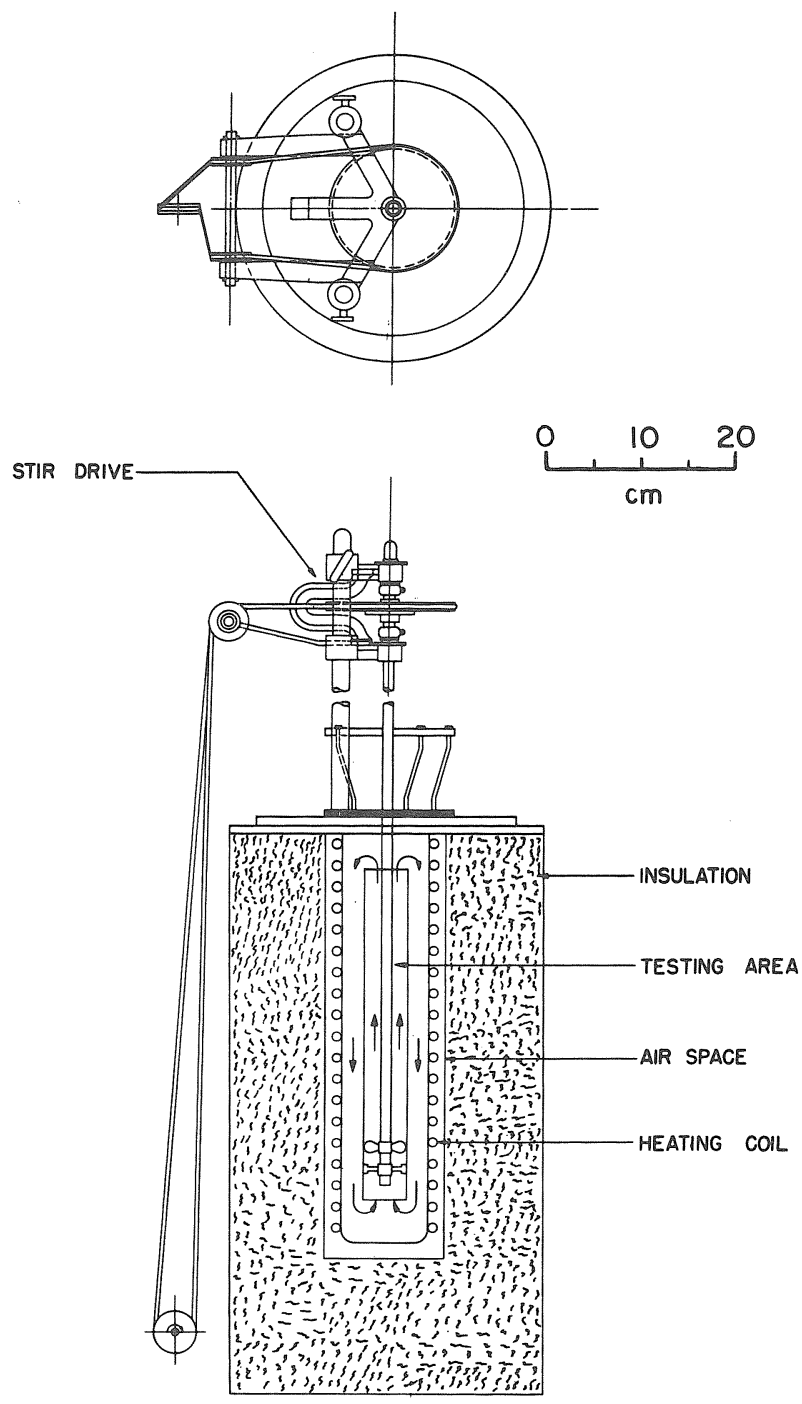

FIgURE 6. Stirred high temperature bath using liquid having freezing point above room temperature.

baths are designed to shield the thermometers from direct radiation from the heating units.

For calibrations in the range 1 to $99^{\circ} \mathrm{C}$ (34 to $210^{\circ} \mathrm{F}$ ) water is used as the bath liquid. One grade of petroleum oil is used between 100 and $200{ }^{\circ} \mathrm{C}$ $\left(212\right.$ to $\left.392{ }^{\circ} \mathrm{F}\right)$ and a second grade between 200 and $300{ }^{\circ} \mathrm{C}\left(392\right.$ and $\left.572^{\circ} \mathrm{F}\right)$. The oils must not have flash points below the highest test temperatures, nor be too viscous to prevent adequate stirring at the lower test temperatures.

Calibrations from -1 to $-110{ }^{\circ} \mathrm{C}\left(30\right.$ to $\left.-166^{\circ} \mathrm{F}\right)$ are made in a cryostat similar to the one described by Scott and Brickwedde [6]. The cryostat, shown in figure 7 , consists of an inner Dewar flask, D, which contains the bath liquid. This flask is surrounded by liquid nitrogen contained in the outer Dewar flask, C. The rate of heat transfer between the bath liquid and the liquid nitrogen is retarded by evacuating the space 


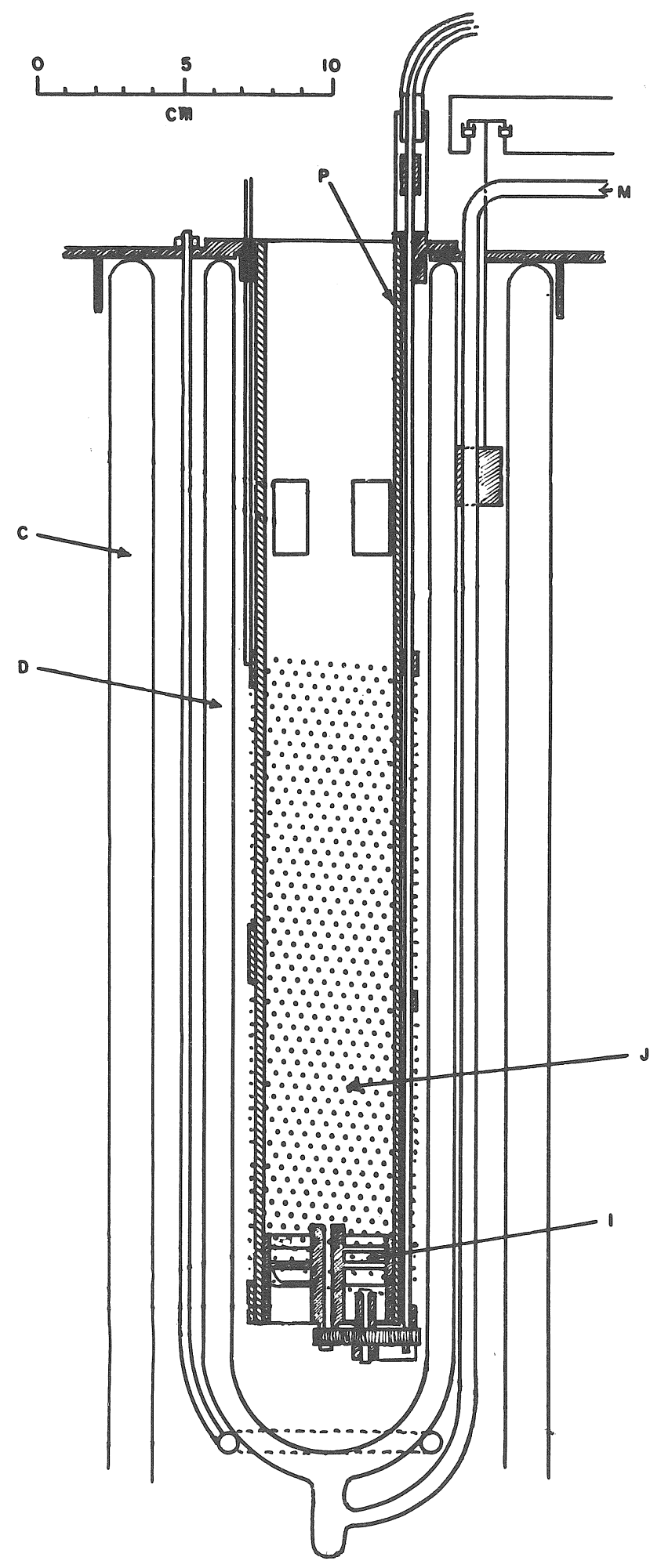

Figure 7. Vertical section of cryostat. between the walls of the inner Dewar flask through the side tube, $M$, which is connected to a vacuum system. Vigorous stirring of the bath liquid is main. tained by the propeller, I, which circulates the liquid around the walls of the stirrer tube, $\mathrm{P}$, similar to the flow of the medium in the high temperature bath. The temperature of the bath is thermostatically controlled by heater coils, J, wound on the outside of the stirrer tube. The thermometers are immersed inside the stirrer tube, thus shielding them from the heater coils.

The bath liquid is a five-component mixture containing by weight 14.5 percent of chloroform, 25.3 percent of methylene chloride, 33.4 percent of ethyl bromide, 10.4 percent of transdichloroethylene, and 16.4 percent of trichloroethylene. This mixture freezes at approximately $-150{ }^{\circ} \mathrm{C}\left(-238^{\circ} \mathrm{F}\right)$, but readily absorbs moisture and becomes cloudy at somewhat higher temperatures. For this reason calibrations are not performed in this bath below $-110^{\circ} \mathrm{C}$ $\left(-166^{\circ} \mathrm{F}\right)$.

A comparison measurement can be made at approximately $-196{ }^{\circ} \mathrm{C}$ (boiling point of nitrogen) and $-183{ }^{\circ} \mathrm{C}$ (boiling point of oxygen). A silvered Dewar flask with a narrow transparent vertical strip is used as a container for the liquid nitrogen or oxygen. The liquid is agitated by bubbling nitrogen or oxygen gas in the corresponding liquid through a glass tube with an outlet near the bottom of the flask.

\subsection{Determination of Scale Corrections}

Thermometers submitted to NBS for test are generally calibrated by starting at the lowest test point requested and advancing to the higher test points. In most cases the ice point is the lowest point. Ice is packed firmly around the thermometer which has been placed in an ice bath and immersed to the proper depth as determined by the type of thermometer. The thermometer is gently tapped before reading to prevent the sticking of a falling meniscus. Care is taken not to tap too vigorously, as this may cause the mercury to rebound to an erroneously high reading.

The thermometer scale corrections quoted in the Report of Calibration apply as long as the ice-point reading remains the same as observed during the NBS calibration. Subsequent changes in the ice-point reading of the thermometer will result from small changes in the glass of the thermometer bulb which affects its volume. The volume of the capillary also changes, but the volume of mercury contained in the stem is so small, in comparison to the amount of mercury in the bulb, that changes in the stem volume can usually be ignored. As a result, changes in the ice-point reading of the thermometer, taken after an exposure of not less than 3 days at a temperature of approximately $23^{\circ} \mathrm{C}$ $\left(73^{\circ} \mathrm{F}\right)$, will be reflected by similar changes in readings at each point along the scale. Therefore, when the correction at the ice point is found to be higher (or lower) than that observed at the time of calibration, the other reported scale corrections will be higher 
(or lower) by the same amount. An example is given below:

Original Corrections from NBS Report

\begin{tabular}{cc}
\hline \hline Temperature & Correction \\
\hline$+0.011^{\circ} \mathrm{C}$ & $-0.011^{\circ} \mathrm{C}$ \\
10.000 & -.015 \\
20.000 & -.020 \\
30.000 & \pm .008 \\
40.000 & -.033 \\
50.000 & .000
\end{tabular}

A later ice-point reading may be $+0.019^{\circ} \mathrm{C}$. This means that the ice-point correction will be $-0.019^{\circ} \mathrm{C}$ and a new set of corrections should be made by subtracting 0.008 from all of the original-corrections. The new table would look as follows:

\begin{tabular}{cc}
\hline \hline Temperature & Correction \\
\hline$+0.019^{\circ} \mathrm{C}$ & $-0.019^{\circ} \mathrm{C}$ \\
10.000 & -.023 \\
20.000 & -.028 \\
30.000 & -.000 \\
40.000 & -.041 \\
50.000 & -.008
\end{tabular}

Once a thermometer has been calibrated, an ice point check is all that is necessary to obtain a current calibration, provided the thermometer has not been abused.
Ice-point readings on the thermometers being calibrated are not taken after each test point on the scale. For thermometers graduated below $300^{\circ} \mathrm{C}$ or $600^{\circ} \mathrm{F}$, ice points are taken before the comparison calibrations and 3 days (with the thermometer at room temperature) after the last test point to assure that the bulb has recovered within acceptable limits. With thermometers graduated above $300^{\circ} \mathrm{C}$ or $600^{\circ} \mathrm{F}$, an ice point is taken and it is immediately tested at the highest test point on the scale. After a rest period of 3 days at room temperature a second ice point is taken. The agreement between the first and second ice point must be within the stated accuracy limit of the thermometer, or it is deemed unsuitable for calibration and no further testing is done.

The ice point is the only test temperature taken in the manner déscribed above. Comparison measurements are made with the temperature of the bath slowly increasing at a steady rate, which does not exceed one scale division in 3 to 10 minutes [7]. All thermometers are read using a 10 power telescope, which is attached to each calibration bath and perpendicular to the thermometers. The telescope is a necessity if errors due to parallax are to be avoided.

When a liquid-in-glass thermometer is intended to be used as a standard, an ice point should be taken after heating it at each test temperature. The adjusted scale correction is determined by adding the ice-point reading to the current correction at the corresponding test temperature. The example shown above is modified in this way.

\begin{tabular}{cccc}
\hline \hline $\begin{array}{c}\text { Test } \\
\text { Temperature }\end{array}$ & $\begin{array}{c}\text { Current } \\
\text { Correction }\end{array}$ & $\begin{array}{c}\text { Ice-Point Reading After } \\
\text { Heating to Test Temperature }\end{array}$ & $\begin{array}{c}\text { Adjusted } \\
\text { Scale Correction }\end{array}$ \\
$+0.019^{\circ} \mathrm{C}$ & $-0.019^{\circ} \mathrm{C}$ & +.019 & $0.000^{\circ} \mathrm{C}$ \\
10.000 & -.023 & +.019 & -.004 \\
20.000 & -.028 & +.017 & -.011 \\
30.000 & -.000 & +.010 & \pm .010 \\
40.000 & -.008 & -.000 & -.041 \\
50.000 & -.008 & .020 & \\
\hline
\end{tabular}

When this thermometer is used as a standard, the ice point should again be taken after each calibration point. To obtain the actual temperature of the bath, the ice-point correction is added to the appropriate adjusted scale correction and thermometer reading. If the calibration temperature is $25^{\circ} \mathrm{C}$, the thermometer reads $24.983{ }^{\circ} \mathrm{C}$, and the ice-point reading taken after the calibration is $+0.014^{\circ} \mathrm{C}$, the actual temperature is computed as follows:

$$
\begin{aligned}
& \text { Thermometer reading } \\
& 24.983^{\circ} \mathrm{C} \\
& \text { Interpolated Adjusted Scale Correction }-.001 \\
& \text { Ice-point correction } \\
& \text { Actual Temperature of Bath Medium }
\end{aligned}
$$

This method eliminates the need to wait 3 days for the bulb to recover and avoids the error due to the ice-point depression (See Sec. 8.1a) that appears when a thermometer is heated. The standard can be used at any time and at any temperature with no concern about the change in bulb volume, provided the ice point is taken after it is used.

It is advisable to use two liquid-in-glass standards when calibrating, in order to detect reading errors and maintain a cross check of the standards. The calibration procedure can best be described by following a hypothetical calibration of four thermometers, $\mathrm{T}_{1}$ through $\mathrm{T}_{4}$.

Table 3 shows hypothetical observations taken in obtaining the corrections applicable to the thermometers at $20^{\circ} \mathrm{C}$. For simplification, all of the entries in the table reflect perfect thermometer performance with a temperature rise of $0.01{ }^{\circ} \mathrm{C}$ between each observation and no observer error. 
TABLE 3. - Comparison of test thermometers with liquid-in-glass standards

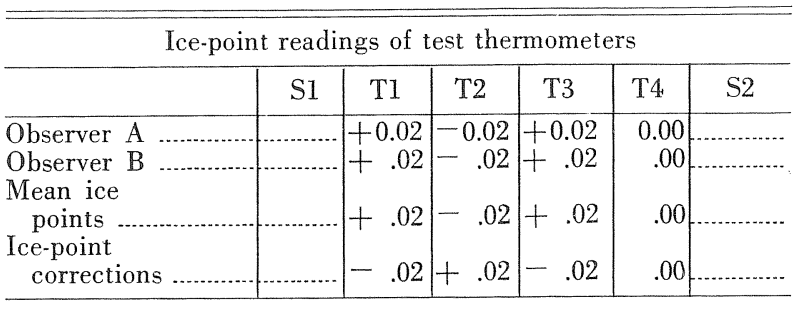

Thermometer comparisons

\begin{tabular}{|c|c|c|c|c|c|c|}
\hline $\begin{array}{l}\text { Observer A reading } \\
\text { left to right }\end{array}$ & 19.87 & 19.98 & 19.96 & 20.02 & 20.03 & 19.89 \\
\hline $\begin{array}{l}\text { Observer A reading } \\
\text { right to left }\end{array}$ & 19.88 & 19.99 & 19.97 & 20.03 & 20.04 & 19.89 \\
\hline $\begin{array}{l}\text { Observer } B \text { reading } \\
\text { left to right }\end{array}$ & 19.88 & 19.99 & 19.97 & 20.04 & 20.05 & 19.90 \\
\hline $\begin{array}{l}\text { Observer B reading } \\
\text { right to left }\end{array}$ & 19.89 & 20.00 & 19.98 & 20.04 & 20.05 & 19.90 \\
\hline Means & 19.88 & 19.99 & 19.97 & 20.03 & 20.04 & $19.89^{5}$ \\
\hline
\end{tabular}

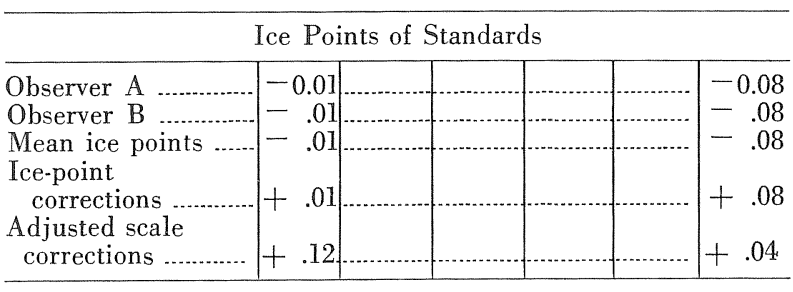

\begin{tabular}{|c|c|c|c|c|c|c|}
\hline \multicolumn{7}{|c|}{ Calculations of corrections } \\
\hline $\begin{array}{l}\text { Correction to } \\
\text { standards }\end{array}$ & +0.13 & & & & & +0.12 \\
\hline $\begin{array}{l}\text { Mean temperature, } \\
\text { each standard. }\end{array}$ & 20.01 & & & & & \\
\hline $\begin{array}{c}\text { Mean temperature } \\
\text { of all readings...... }\end{array}$ & & & 20.01 & & & \\
\hline $\begin{array}{l}\text { Corrections to test } \\
\text { thermometers...... }\end{array}$ & & +0.02 & +0.04 & -0.02 & -0.03 & .............. \\
\hline
\end{tabular}

The first observations are the ice points of the thermometers under test. The test thermometers are then mounted in the comparison bath between the two standards. It is preferable to have two observers (A and B). Observer A reads in the order left to right as the thermometers appear in the table, and immediately repeats the observations in the order right to left, while observer B records the data. Observer B promptly reads in the same manner while observer A records. The bath temperature is increasing linearly with time and the observations are spaced uniformly in time. For this reason the mean of the observations with any one thermometer will correspond to the mean temperature value of the comparison bath medium during the observations of all of the thermometers. Immediately after the comparison observations, ice points of the two standards are observed and recorded. With the ice point data and the adjusted scale corrections for the standards, the temperatures indicated by the standards are calculated, and an overall mean temperature for the observations is obtained. This mean temperature is compared with the mean of the observations for each thermometer to obtain a correction to the scale of the thermometers. The thermometer comparisons are repeated in the same manner at the next higher test point until the calibration is completed.

When a platinum resistance thermometer is used as a standard, the sequence of observations is the same, except that the one resistance thermometer is read in place of the separate observations of two liquidin-glass standards. For more information on platinum resistance thermometers refer to NBS Monograph 126, Platinum Resistance Thermometry, available from the Superintendent of Documents, U. S. Government Printing Office, Washington, D. C. 20402.

\subsection{Corrections for Emergent Stem}

When a thermometer is calibrated and used under conditions of total immersion, no difficulty is encountered when the reported scale corrections are to be applied. The temperature of the thermometer bulb and the portion of the stem containing the mercury is definitely defined as the temperature of the bath medium. The corrections apply as given on the report, when this thermometer is used at total immersion.

Occasionally it becomes necessary to use a totalimmersion thermometer with a portion of the stem emergent from the bath medium. The temperature of the environment above the bath, or apparatus.containing the thermometer, may differ markedly from the temperature of the thermometer bulb. It is also possible to have pronounced temperature gradients along the length of exposed mercury column. A correction can be calculated to account for the difference in temperature between the bulb and the emergent stem. A reliable estimate of the mean temperature of the emergent stem is required and should actually be measured. The determination of the stem temperature should be repeated each time the thermometer is used in this way, or the accuracy of the correction will depend upon the constancy of the environmental temperature over a period of time. Significant variations in the temperature of the emergent stem may occur due to air circulation and variations in ambient temperature, even though the location of the thermometer does not change.

The same situation occurs in the case of partialimmersion thermometers. The reported scale corrections apply only for the indicated depth of immersion and a particular stem temperature. If the thermometer is used under conditions other than specified, the reported scale corrections are no longer applicable, and a stem temperature correction is required.

The following paragraphs describe methods for determining stem temperatures and calculating corrections. It will be seen how important the stem temperature correction is in relation to a desired accuracy.

\section{a. Measurement of Emergent-Stem Temperature}

There are two methods available for measuring the approximate mean temperature of the emergent stem. The first method consists of placing one or more small 
auxiliary thermometers near the emergent stem as shown in figure $8(\mathrm{c})$. For a more accurate measurement faden or thread thermometers $[8,9]$ can be used. These thermometers have long bulbs measuring variously 5 to $20 \mathrm{~cm}$, with wall thicknesses and bore sizes nearly the same as the stem of an ordinary thermometer. The bulb length is selected to approximate that of the emergent stem whose temperature is to be measured. The stem of the faden thermometer has a finer capillary than the bulb and is usually graduated in intervals of 2,5 , or 10 degrees Celsius. Stem temperature measurements taken at NBS are based upon the use of faden thermometers whenever possible.

A convenient method for measuring the emergentstem temperature of a total-immersion thermometer that is used at partial immersion involves the use of a faden thermometer. The top of the faden thermometer bulb is placed on a horizontal plane with the top of the mercury column of the thermometer whose stem temperature is being measured. The faden thermometer chosen must have a bulb which is long enough to cover the vertical area of unknown temperature gradient necessary to be measured. This sometimes involves placing part of the faden thermometer bulb in the bath medium, since the top portion of the medium can be at a temperature different from the temperature of the total-immersion thermometer bulb. (This is especially true for measurements above $150{ }^{\circ} \mathrm{C}$ ). The reading of the faden thermometer will indicate the mean temperature value of the area surrounding the bulb, which is also the mean temperature value of the adjacent portion of the total-immersion thermometer stem. A faden thermometer used in this manner is illustrated in figure $8(\mathrm{a})$.

If the stem temperature of a partial-immersion thermometer is to be measured, a similar approach is followed. In this case it is necessary to measure the mean temperature from the immersion line to the top of the mercury column of the partial-immersion thermometer. One or more faden thermometers with appropriate bulb lengths are chosen to accomplish this measurement. This procedure is shown in figure $8(\mathrm{~b})$.

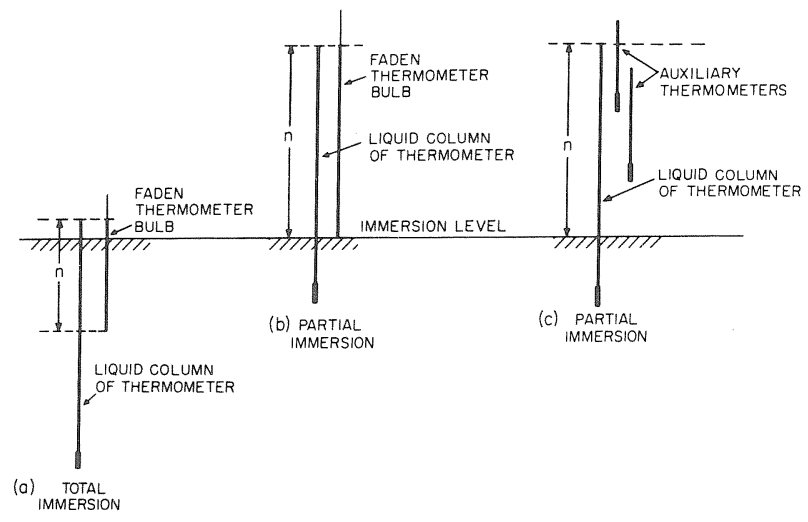

Figure 8. Schemes for measurement of emergent-stem temperature.
In calculating the emergent stem correction, it is convenient to express the length of the thermometer stem adjacent to the faden bulb in terms of degrees on the thermometer scale. If a faden thermometer, having a bulb which is $10 \mathrm{~cm}$ long, is used for a stem temperature measurement, then the number of degrees corresponding to the $10 \mathrm{~cm}$ length must be found by measuring a portion of the thermometer scale. This measurement should be made over the portion of the graduated scale which was adjacent to the faden thermometer bulb. This is particularly important with high-temperature thermometers, where the length of a degree is generally not the same throughout the entire length of the scale. In some instances the adjacent portion of the thermometer stem is not graduated. This is especially true with partial-immersion thermometers in the area above the immersion line. This ungraduated length between the immersion line and the first graduation must be evaluated in terms of scale degrees and included as part of the distance covered.

\section{b. Formula for Total-Immersion Thermometers}

When a thermometer which has been graduated and calibrated for use at total immersion is actually used at partial immersion, the correction for the emergent stem may be calculated by the general formula,

$$
\text { stem correction }=k n\left(t_{1}-t\right) \text {. }
$$

where

$$
\begin{aligned}
k= & \text { differential expansion coefficient of mercury } \\
& \text { (or other thermometric liquid) in the particu- } \\
& \text { lar kind of glass which the thermometer is } \\
& \text { made (see table } 4 \text { ), }
\end{aligned}
$$

The coefficient $k$ varies for different kinds of glass, or for different temperature intervals, i.e., different values of $\left(t_{1}-t\right)$. For purposes of computing the emergent-stem correction, the value of $k$ may be considered as depending on the average of $t_{1}$ and $t$. Values of $k$ as the function of $\left(t_{1}+t\right) / 2$ for two widely used thermometric glasses are given in table 4. If the kind of glass is not known, it is acceptable to use $k=0.00016$ for mercury thermometers graduated in degrees Celsius and $k=0.00009$ for mercury thermometers graduated in degrees Fahrenheit.

The expansions of liquids such as alcohol, toluene, etc., vary quite rapidly with the temperature causing $k$ to vary considerably for different temperature intervals. An approximate stem correction for such thermometers may be calculated by setting the value of $k$ in the above equation as equal to 0.001 for Celsius thermometers or 0.0006 for Fahrenheit thermometers.

Calculation of the stem correction may be illustrated by the following example: A total-immersion thermometer indicates a reading of $90{ }^{\circ} \mathrm{C}$ in a bath when 
TABLE 4, - Values of $k$ for mercury-in-glass thermometers

\begin{tabular}{ll}
\hline \hline Mean temperature & $k$ for "normal" glass $\quad k$ for "borosilicate" glass \\
$\frac{t_{1}+t}{2}$ &
\end{tabular}

For Celsius thermometers

\begin{tabular}{rrr}
\hline $0^{\circ}$ & 0.000158 & 0.000164 \\
100 & .000158 & .000164 \\
150 & .000158 & .000165 \\
200 & .000159 & .000167 \\
250 & .000161 & .000170 \\
300 & .000164 & .000174 \\
350 & $\ldots \ldots \ldots \ldots \ldots$ & .000178 \\
400 & $\ldots \ldots \ldots \ldots$ & .000183 \\
450 & $\ldots \ldots \ldots \ldots$ & .000188 \\
\hline
\end{tabular}

For Fahrenheit thermometers

\begin{tabular}{rrr}
\hline $0^{\circ}$ & 0.000088 & 0.000091 \\
200 & .000088 & .000091 \\
300 & .000088 & .000092 \\
400 & .000089 & .000093 \\
500 & .000090 & .000095 \\
600 & .000092 & .000097 \\
700 & $\ldots \ldots \ldots \ldots \ldots$ & .000100 \\
800 & $\ldots \ldots \ldots \ldots . .$. & .000103
\end{tabular}

immersed to the $80^{\circ} \mathrm{C}$ graduation mark on the scale. A $10 \mathrm{~cm}$ faden thermometer placed alongside the thermometer is adjacent to the scale between the 60 and $90^{\circ} \mathrm{C}$ graduations and indicates a stem temperature of $80^{\circ} \mathrm{C}$. For this case $n=90-60$ or 30 degrees. The stem correction is:

$$
0.00016 \times 30(90-80)=+0.048{ }^{\circ} \mathrm{C} .
$$

This correction is added to the corrected thermometer reading to obtain the actual temperature of the bath medium. Note that when the temperature of the emergent stem is lower than the bath temperature, the sign of the correction is + , since the thermometer would indicate a higher temperature reading if immersed properly.

If a faden thermometer was not available in the above example, the emergent-stem temperature could be estimated by suspending a small auxiliary thermometer above the bath adjacent to the thermometer. The bulb of the auxiliary thermometer would be placed at the center of the emergent stem or at the $85^{\circ} \mathrm{C}$ graduation. The reading of the auxiliary thermometer will indicate the approximate mean temperature of the 10 degrees $\left(80^{\circ}\right.$ to $\left.90^{\circ} \mathrm{C}\right)$ emergent from the bath. For this correction the value for $n$ would be 10 . If the auxiliary thermometer indicates a reading of $60^{\circ} \mathrm{C}$, the stem correction would be:

$$
0.00016 \times 10(90-60)=+0.048^{\circ} \mathrm{C} \text {. }
$$

This method is not usually as reliable as the method involving the use of a faden thermometer [9].

\section{c. Formula for Partial-Immersion Thermometers}

The scale corrections for partial-immersion thermometers calibrated at NBS are applicable when the thermometer is immersed to the immersion mark and, unless otherwise requested, for the unspecified stem temperatures which prevailed over the comparison baths at the time of calibration. Frequently it is necessary to report scale corrections which are applicable when specified mean temperatures of the emergent stem are requested. In such cases the emergent stem temperatures are measured during calibration and the observations are corrected as necessary to account for any differences found between the specified stem temperatures and the stem temperatures observed during test. The magnitude of the stem correction will be proportional to the difference between the specified and observed stem temperatures, and may be calculated for Celsius mercurial thermometers by using the following formula:

$$
\text { stem correction }=0.00016 n\left(t_{\mathrm{sp}}-t_{\mathrm{obs}}\right),
$$

where

$$
\begin{aligned}
t_{\mathrm{sp}}= & \text { specified mean temperature of the emergent } \\
& \text { stem (for which reported scale corrections } \\
& \text { apply), } \\
t_{\mathrm{obs}}= & \text { observed mean temperature of the emergent } \\
& \text { stem (faden thermometer reading), } \\
n= & \text { number of scale degrees equivalent to the } \\
& \text { length of emergent stem (including the eval- } \\
& \text { uated area above the immersion line) }
\end{aligned}
$$


This formula may also be used to correct the indications of a partial-immersion thermometer, when, during use, the actual stem temperatures differ from the specified ones for which the scale corrections apply.

\section{d. Formula for Calorimetric Thermometers}

The stem correction is often important when thermometers are used for differential temperature measurements, as in calorimetry (Sec. 6.5). The correction may be computed from the following formula, which involves the difference between the initial and final readings, provided the mean temperature of the stem remains constant.

Stem correction $=k d\left(t_{\mathrm{r}}+t_{\mathrm{F}}-I-t\right)$,

where

$$
\begin{aligned}
& k=\text { factor for relative expansion of glass and } \\
& \text { mercury, } \\
& t_{\mathrm{I}}=\text { initial reading, } \\
& t_{\mathrm{F}}=\text { final reading, } \\
& I=\text { scale reading to which the thermometer is } \\
& \quad \text { immersed, } \\
& t=\text { mean temperature of the emergent stem, } \\
& d=t_{\mathrm{F}}-t_{\mathrm{r}}
\end{aligned}
$$

This correction must be applied (added if positive, subtracted if negative) to the difference of the readings to give the actual temperature difference.

Example: The thermometer was immersed to the $20^{\circ}$ mark; the initial reading, $t \mathrm{r}$, was $25^{\circ} \mathrm{C}$; the final reading, $t_{\mathrm{F}}$, was $30^{\circ} \mathrm{C}$; and the stem temperature was $20{ }^{\circ} \mathrm{C}$. The correction is:

$$
0.00016 \times 5(25+30-20-20)=+0.012{ }^{\circ} \mathrm{C} \text {. }
$$

Since the difference between $t_{\mathrm{r}}$ and $t_{\mathrm{F}}$ was $5^{\circ}$, the actual difference between the initial and final temperature readings was:

$$
t_{\mathrm{F}}-t_{\mathrm{r}}+\text { correction }=5.012^{\circ} \mathrm{C} \text {. }
$$

\section{e. Formula for Beckmann Thermometers}

The formula used to compute the stem temperature correction for Beckmann thermometers (Sec. 6.4) is similar to the one used for calorimetric thermometers. The formula given below is applicable provided the thermometer is immersed near the zero degree indication on the scale and the temperature of the stem remains constant.

$$
\text { stem correction }=k d\left(S+t_{\mathrm{r}}+t_{\mathrm{r}}-t\right),
$$

where

$$
\begin{aligned}
& k=\text { factor for relative expansion of glass and } \\
& \text { mercury, } \\
& t_{\mathrm{I}}=\text { initial reading, } \\
& \mathrm{t}_{\mathrm{F}}=\text { final reading, } \\
& t=\text { mean temperature of the emergent stem, } \\
& d=t_{\mathrm{F}}-t_{\mathrm{r}} \\
& S=\text { setting of the thermometer (Sec. 6.4). }
\end{aligned}
$$

A Beckmann thermometer should not be used with any part of the lower portion of the stem exposed to ambient temperature. Since this part may contain 5 to 10 times more mercury per centimeter than the graduated portion, a large and uncertain error will be introduced if this section is not in the bath medium. If it is unavoidable, and such a thermometer must be used in this way, the necessary correction may be computed from the above formula, provided $S$ in the formula is replaced by $S+m$, where $m$ is the number of degrees the temperature of the thermometer must be lowered to bring the meniscus from the zero mark on the scale to the point of immersion.

If the thermometer is immersed to some point other than the zero mark, as would ordinarily be the case with thermometers having the zero graduation at the top of the scale, the differential stem correction may be calculated from the above formula if $S$ is replaced by $S+m$. The formula is applicable whether the point of immersion is on the scale or below it, provided the points at which readings are made are above the point to which the thermometer is immersed.

\subsection{Number and Choice of Test Points}

A thermometer is usually calibrated at points spaced uniformly over the entire range of the main scale. The number of calibration points chosen depends on the range of scale, graduation interval, and accuracy desired. The interval between the calibration points should not be unnecessarily small, nor should it be so large as to destroy confidence in interpolated corrections for temperature values between the calibration points.

For thermometers not graduated above approximately $200{ }^{\circ} \mathrm{C}$, it is generally accepted that the interval between test points should not exceed 100 scale divisions, if the corrected temperature values between the calibration points are to have an expected accuracy of approximately one-half of one scale division. If accuracies of one or two-tenths of a scale division are desired, it will be necessary to reduce the calibration interval to every 40 or 50 scale divisions. If a thermometer is graduated above $200{ }^{\circ} \mathrm{C}$, a 40 to 50 scale division calibration interval is required to produce corrected temperature values with expected accuracies of approximately one-half of a scale division, and a 20 to 25 scale division calibration interval is necessary for expected accuracies to be approximately one or two-tenths of a scale division.

The above results were derived from analysis of calibration data taken on more than 50 thermometers purchased from 1930 through 1956 for use as laboratory standards. The data indicated that there was considerable variation between individual thermometers and that scale corrections obtained over a given interval for a particular thermometer were not sufficient to predict whether or not more calibration points were required. The above studies were made with only a few of the many types of thermometers submitted to NBS for calibration, and may not necessarily be 
applicable to other types. Experience with a particular type of thermometer seems to be the most reliable guide in the choice of its calibration points.

If a thermometer is submitted to NBS for calibration and the calibration points are not specified on the purchase order, it will be tested at a reference point and at intervals of approximately every 100 scale divisions. A calibration should never consist of fewer than two points on the main scale, and should always be tested at a reference point, whether on the main scale or on an auxiliary scale.

\section{Common Thermometers and Factors Affecting Their Use}

A listing of tolerances and expected accuracies for common types of liquid-in-glass thermometers, which are accepted for calibration, are given in tables 5 through 12. The scale tolerances shown are chosen to be indicative of good manufacturing practice. When a thermometer is manufactured, small errors in pointing (marks placed on a blank thermometer at various temperatures to be used as guides for the placement of the graduation lines) and graduating are inevitable. These graduation marks are also subject to variations due to the inherent properties of the glass. The tolerances must be sufficiently restrictive to insure a satisfactory high-grade thermometer, and at the same time not cause undue manufacturing difficulties.

In addition to the scale tolerance limit, the error in any temperature interval should not exceed 5 percent of the nominal value of the interval. The purpose of this requirement is to eliminate thermometers having large corrections of alternating signs, which lead to uncertainties in the interpolation of scale corrections between the calibration points.

The word "accuracy" used in these tables refers to the best values attainable in the use of thermometers when all corrections are applied. The accuracy bounds may seem broad in some instances, but the definite limitations of liquid-in-glass thermometry become ap. parent when all factors are considered. For example, if the scale is expanded by reducing the diameter of the capillary, a practical limit is reached beyond which capillary forces, in combination with the elasticity of the thermometer bulb, will prevent a smooth advance or retreat of the mercury column. The movement of the mercury meniscus may be erratic and occur in steps appreciably large in comparison to the graduation interval. This is particularly true when the temperature of the medium is decreasing. Less rigid bulbs (relatively large diameters and/or thin walls), as well as capillaries of small diameters, may cause large "meniscus jumps." Excessively elliptical or flattened bores are not recommended for the same reason. Therefore, increasing the length of a degree on the scale, for practical bulb sizes, improves thermometric performance only to a certain point. Beyond this point precision of reading may readily be mistaken for accuracy in temperature measurement. A study of the effects of bulb and capillary dimensions on thermometer performance, made by Hall and Leaver [10], provides valuable guidelines for design purposes.
Other factors such as ice-point changes, unless exactly accounted for, and differences in external pres. sure may also account for inaccuracies much greater than the imprecision with which a scale having 0.1 or 0.2 degree graduations may be read.

\subsection{Total-Immersion Thermometers}

Thermometers pointed and graduated by the manufacturer to indicate correct temperatures when the bulb and the portion of the stem containing the thermometric liquid are subjected to the temperature being measured are known as total-immersion thermometers. While these thermometers are designed for immersion of all the mercury, it is not desirable to immerse the portion of the stem above the meniscus. The heating of this portion to high temperatures could cause excessive gas pressures resulting in erroneous readings and possibly permanent damage to the bulb.

In practice, a short length of the mercury column often must be left emergent from the bath or medium being measured so that the meniscus is visible. If the temperature difference between the bath medium and its surroundings is large, an appreciable temperature gradient may exist around the thermometer stem near the surface of the bath. This condition becomes more serious when a total-immersion thermometer is intentionally used at partial immersion. If either situation exists, an emergent stem correction, as explained in section $5.3 \mathrm{~b}$, will be necessary. The correction may be as large as 20 Celsius degrees (36 Fahrenheit degrees) if the length of the emergent liquid column and the difference in temperature between the bath and the space above it are large. Tolerances and accuracies expected of total-immersion thermometers are given in tables 5 and 6.

\subsection{Partial-Immersion Thermometers}

In many instances the use of a total-immersion liquid-in-glass thermometer for temperature measurements is inconvenient or impossible. For this reason partial-immersion thermometers are designed with scales graduated to indicate correct temperatures when the thermometers are immersed to specified depths. Unless otherwise stated, each Report of Calibration issued by NBS gives corrections which are applicable for temperatures prevailing above the comparison baths. No stem temperature correction is necessary when 
TABlE 5. - Tolerances for Celsius total-immersion mercury thermometers

\begin{tabular}{c|c|c|c}
\hline $\begin{array}{c}\text { Temperature range in } \\
\text { degrees }\end{array}$ & $\begin{array}{c}\text { Graduation } \\
\text { interval in } \\
\text { degrees }\end{array}$ & $\begin{array}{c}\text { Tolerance } \\
\text { in } \\
\text { degrees }\end{array}$ & $\begin{array}{c}\text { Accuracy } \\
\text { in degrees }\end{array}$ \\
\hline
\end{tabular}

Thermometer graduated under $150{ }^{\circ} \mathrm{C}$

\begin{tabular}{|c|c|c|c|}
\hline $\begin{array}{l}{ }^{\circ} \mathrm{C} \\
0 \text { up to } 150\end{array}$ & 70 or 05 & 0.5 & 01 \\
\hline 0 up to 150 & $\begin{array}{r}1.0010 .0 \\
.2\end{array}$ & $\begin{array}{r}0.0 \\
.4\end{array}$ & $\begin{array}{c}0.1 \text { to } 0.2 \\
.02 \text { to } .05\end{array}$ \\
\hline 0 up to 100 & .1 & .3 & .01 to .03 \\
\hline
\end{tabular}

Thermometers graduated under $300{ }^{\circ} \mathrm{C}$

\begin{tabular}{|c|c|c|c|c|}
\hline $\left.\begin{array}{l}0 \text { up to } 100 \\
\text { A bove } 100 \text { up to } 300 \\
0 \text { up to } 100 \\
\text { Above } 100 \text { up to } 200 \ldots\end{array}\right\}$ & 1.0 or 0.5 & & $\begin{array}{r}0.5 \\
1.0 \\
0.4 \\
.5\end{array}$ & $\begin{array}{l}0.1 \text { to } 0.2 \\
.2 \text { to } .3 \\
.02 \text { to } .05 \\
.05 \text { to } .1\end{array}$ \\
\hline
\end{tabular}

Thermometers graduated above $300{ }^{\circ} \mathrm{C}$

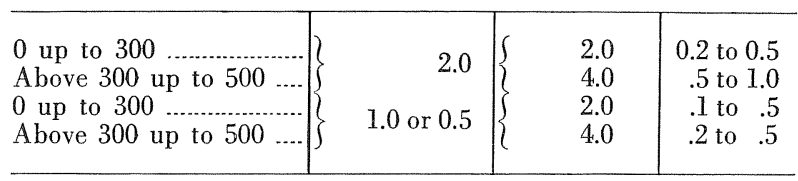

TABLE 6. - Tolerances for Fahrenheit total-immersion mercury thermometers

\begin{tabular}{c|c|c|c}
\hline \hline $\begin{array}{c}\text { Temperature range in } \\
\text { degrees }\end{array}$ & $\begin{array}{c}\text { Graduation } \\
\text { interval in } \\
\text { degrees }\end{array}$ & $\begin{array}{c}\text { Tolerance } \\
\text { in } \\
\text { degrees }\end{array}$ & $\begin{array}{c}\text { Accuracy } \\
\text { in degrees }\end{array}$ \\
\hline
\end{tabular}

Thermometers graduated under $300^{\circ} \mathrm{F}$

\begin{tabular}{|c|c|c|c|}
\hline 32 up to 300 & 2.0 & 1.0 & 0.2 to 0.5 \\
\hline 32 up to 300 & 1.0 or 0.5 & 1.0 & .1 to .2 \\
\hline 32 up to 212 & .2 or .1 & 0.5 & .02 to .05 \\
\hline
\end{tabular}

Thermometers graduated under $600^{\circ} \mathrm{F}$

\begin{tabular}{|c|c|c|c|c|}
\hline $\left.\begin{array}{l}32 \text { up to } 212 \\
\text { Above } 212 \text { up to } 600 \ldots\end{array}\right\}$ & 2 or 1 & & $\begin{array}{l}1.0 \\
2.0\end{array}$ & 0.2 to 0.5 \\
\hline
\end{tabular}

Thermometers graduated above $600^{\circ} \mathrm{F}$

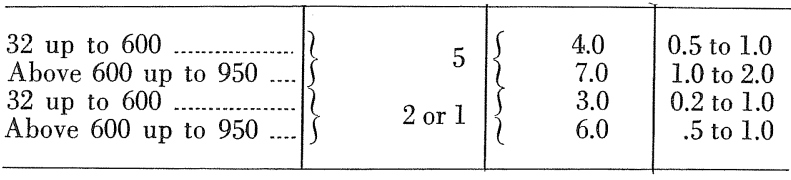

these thermometers are used under conditions similar to those existing during calibration. However, if conditions differ, especially the temperature of the emergent stem, the necessary emergent stem correction must be calculated as shown in section 5.3c. An unsteady or irreproducible environment surrounding the

emergent stem, $t$ gether with the inherent difficulty of estimating or measuring the emergent-stem temperature with sufficient accuracy, can contribute markedly to the uncertainty of a given thermometer indication. For these reasons tolerances and accuracies expected of partial-immersion thermometers, as given in tables 7 and 8 , are not as stringent as those for total-immersion thermometers.

\section{TABLE 7. - Tolerances for Celsius partial-immersion mercury thermometers}

\begin{tabular}{c|c|c|c}
\hline \hline $\begin{array}{c}\text { Temperature range in } \\
\text { degrees }\end{array}$ & $\begin{array}{c}\text { Graduation } \\
\text { interval in } \\
\text { degrees a }\end{array}$ & $\begin{array}{c}\text { Toler- } \\
\text { ance in } \\
\text { degrees }\end{array}$ & $\begin{array}{c}\text { Accuracy b } \\
\text { in degrees }\end{array}$ \\
\hline
\end{tabular}

Thermometers not graduated above $150{ }^{\circ} \mathrm{C}$

\begin{tabular}{|c|c|c|c|}
\hline 0 up to 100 & 1.0 or 0.5 & 1.0 & 0.1 to 0.3 \\
\hline 0 up to 150 & 1.0 or 0.5 & 1.0 & 0.1 to 0.5 \\
\hline
\end{tabular}

Thermometers not graduated above $300{ }^{\circ} \mathrm{C}$

\begin{tabular}{|r|r|r|r}
\hline 0 up to $100 \ldots \ldots$ & 1.0 & 1.0 & 0.1 to 0.3 \\
Above 100 up to $300 \ldots . . .$. & 1.0 & 1.5 & .5 to 1.0 \\
\hline
\end{tabular}

Thermometers graduated above $300{ }^{\circ} \mathrm{C}$

\begin{tabular}{|c|c|c|c|c|}
\hline $\begin{array}{l}0 \text { up to } 300 \\
\text { Above } 300 \text { up to } 500\end{array}$ & 2.0 or 1.0 & $\zeta$ & $\begin{array}{l}2.5 \\
5.0\end{array}$ & $\begin{array}{l}0.5 \text { to } 1.0 \\
1.0 \text { to } 2.0\end{array}$ \\
\hline
\end{tabular}

TABLE 8. - Tolerances for Fahrenheit partial-immersion mercury thermometers

\begin{tabular}{c|c|c|c}
\hline $\begin{array}{c}\text { Temperature range in } \\
\text { degrees }\end{array}$ & $\begin{array}{c}\text { Graduation } \\
\text { interval in } \\
\text { degrees a }\end{array}$ & $\begin{array}{c}\text { Toler- } \\
\text { ance in } \\
\text { degrees }\end{array}$ & $\begin{array}{l}\text { Accuracy b } \\
\text { in degrees }\end{array}$ \\
\hline
\end{tabular}

Thermometers not graduated above $300^{\circ} \mathrm{F}$

\begin{tabular}{|c|c|c|c|}
\hline 32 up to 212 . & 2.0 or 1.0 & 2.0 & 0.2 to 0.5 \\
\hline 32 up to 300 & 2.0 or 1.0 & 2.0 & 0.2 to 1.0 \\
\hline
\end{tabular}

Thermometers not graduated above $600^{\circ} \mathrm{F}$

32 up to 212 .

Above 212 up to 600 .

Thermometers graduated above $600^{\circ} \mathrm{F}$

\begin{tabular}{|c|c|c|c|c|c|}
\hline $\begin{array}{l}32 \text { up to } 600 \\
\text { Above } 600 \text { up to } 950 . . .\end{array}$ & \} & 5.0 or 2.0 & 1 & $\begin{array}{r}5.0 \\
10.0\end{array}$ & $\begin{array}{l}1.0 \text { to } 2.0 \\
2.0 \text { to } 3.0\end{array}$ \\
\hline
\end{tabular}

a Partial-immersion thermometers are sometimes graduated in smaller intervals than shown in these tables, but this in no way improves the performance of the thermometers, and the listed tolerances and accuracies still apply.

b The accuracies shown are attainable only if emergent stem temperatures are closely known and accounted for. 


\subsection{Low-Temperature Thermometers}

The use of mercury-in-glass thermometers for low temperature measurements is limited by the freezing point of mercury, which is $-38.9^{\circ} \mathrm{C}\left(-38.0^{\circ} \mathrm{F}\right)$. This limit may be extended to lower temperatures by forming an eutectic alloy consisting of mercury and 8.5 percent by weight of thallium. The freezing point of this alloy is approximately $-59^{\circ} \mathrm{C}\left(-74{ }^{\circ} \mathrm{F}\right)$. How. ever, small differences in the quantity of thallium present have the effect of markedly raising the freezing point of the alloy. It has also been found that some thermometers containing this liquid have behaved erratically in the range of -59 to $-57^{\circ} \mathrm{C}$. Consequently, thermometers using a mercury-thallium alloy as the liquid should not be used below $-56^{\circ} \mathrm{C}$ $\left(-69^{\circ} \mathrm{F}\right)$.

Temperature measurements from $-56{ }^{\circ} \mathrm{C}(-69$ $\left.{ }^{\circ} \mathrm{F}\right)$ to approximately $-200{ }^{\circ} \mathrm{C}\left(-328{ }^{\circ} \mathrm{F}\right)$ can be made by using thermometers containing organic liquids. Alcohol, toluene, pentane, or other organic liquids, alone or in mixtures, have been used as fluids for low temperature thermometers. All of these fluids have limitations, and thermometers containing organic liquids are not considered to be as reliable as thermometers containing mercury or mercury-thallium alloy.

Organic liquids have the disadvantage of wetting a surface and leaving a film on the wall of the capillary when the liquid column recedes. This may lead to significant errors in the temperature indications if sufficient precautions are not taken. The thickness of the film on the capillary wall will depend, among other things, on the viscosity of the liquid, the interfacial action between the liquid and glass, and the rate at which the thermometer is cooled. Whenever possible the rate of cooling should be slow with the bulb cooled first, enabling the viscosity of the organic fluid in the capillary to be kept as low as possible until the final temperature is reached. This minimizes the amount of liquid left on the capillary wall. Sufficient time should always be allowed to assure complete drainage. Under adverse conditions this may take an hour or more.

In addition to good drainage characteristics, a satis. factory low-temperature fluid should not contain water, dirt, or other foreign material which will separate from the liquid. Because low-temperature thermometers are frequently designed for use above room temperature, the vapor pressure of the liquid must be low to prevent distillation at these higher temperatures. Any dye, added to the fluid for improved visibility, should be chosen for good color fastness with respect to light exposure or chemical action with the organic liquid.

Tolerances and accuracies applicable to low-temperature thermometers are given in tables 9 and 10 .
TABLE 9. - Tolerances for low-temperature total-immersion thermometers

\begin{tabular}{c|c|c|c|c}
\hline $\begin{array}{c}\text { Temperature } \\
\text { range in } \\
\text { degrees }\end{array}$ & $\begin{array}{c}\text { Type of } \\
\text { thermometer }\end{array}$ & $\begin{array}{c}\text { Graduation } \\
\text { interval in } \\
\text { degrees }\end{array}$ & $\begin{array}{l}\text { Toler- } \\
\text { ance in } \\
\text { degrees }\end{array}$ & $\begin{array}{c}\text { Accuracy } \\
\text { in degrees }\end{array}$ \\
\hline
\end{tabular}

Celsius thermometers

\begin{tabular}{|c|c|c|c|c|}
\hline $\begin{array}{l}-35 \text { to } 0 \\
-35 \text { to } 0 \\
-56 \text { to } 0 \\
-56 \text { to } 0 \\
-200 \text { to } 0\end{array}$ & 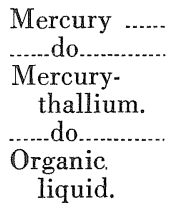 & $\begin{array}{r}1 \text { or } 0.5 \\
.2 \\
.5 \\
\\
.2 \\
1.0\end{array}$ & $\begin{array}{r}0.5 \\
.4 \\
.5 \\
.4 \\
2.0\end{array}$ & $\begin{array}{c}0.1 \text { to } 0.2 \\
.02 \text { to } .05 \\
.1 \text { to } .2 \\
\\
.02 \text { to } \\
.2 \text { to } .5\end{array}$ \\
\hline
\end{tabular}

Fahrenheit thermometers

\begin{tabular}{|c|c|c|c|c|}
\hline-35 to 32 & Mercury ....... & 1 or 0.5 & 1.0 & 0.1 to 0.2 \\
\hline-35 to 32 & ..... do & & 0.5 & .05 \\
\hline-69 to 32 & $\begin{array}{l}\text { Mercury- } \\
\text { thallium. }\end{array}$ & 1 or .5 & 1.0 & .1 to .2 \\
\hline-69 to 32 & do & .2 & 0.5 & .05 \\
\hline-328 to 32 & $\begin{array}{l}\text { Organic. } \\
\text { liquid. }\end{array}$ & 2 or 1.0 & 3.0 & .3 to .5 \\
\hline
\end{tabular}

Table 10. - Tolerances for low-temperature partial-immersion thermometers

\begin{tabular}{c|c|c|c|c}
\hline $\begin{array}{c}\text { Temperature } \\
\text { range in } \\
\text { degrees }\end{array}$ & $\begin{array}{c}\text { Type of } \\
\text { thermometer }\end{array}$ & $\begin{array}{c}\text { Graduation } \\
\text { interval in } \\
\text { degrees }\end{array}$ & $\begin{array}{c}\text { Toler- } \\
\text { ance in } \\
\text { degrees }\end{array}$ & $\begin{array}{c}\text { Accuracy } \\
\text { in degrees }\end{array}$ \\
\hline
\end{tabular}

Celsius thermometers

\begin{tabular}{l|l|l|r|r}
\hline-35 to 0 & $\begin{array}{l}\text { Mercury ..... } \\
\text { Mercury- } \\
\text { thallium. }\end{array}$ & $\begin{array}{l}1.0 \text { or } 0.5 \\
1.0 \text { or } .5\end{array}$ & 0.5 & $\begin{array}{c}0.2 \text { to } 0.3 \\
.2 \text { to } .3 \\
\text { Organic } \\
\text { liquid. }\end{array}$
\end{tabular}

Fahrenheit thermometers

\begin{tabular}{|c|c|c|c|c|}
\hline-35 to 32 & Mercury ........ & 1.0 or 0.5 & 1 & 0.3 to 0.5 \\
\hline-69 to 32 & $\begin{array}{l}\text { Mercury- } \\
\text { thallium. }\end{array}$ & 1.0 or .5 & 1 & .3 to .5 \\
\hline-130 to 32 & $\begin{array}{l}\text { Organic } \\
\text { liquid. }\end{array}$ & 2 or 1 & 5 & .8 to 2.0 \\
\hline
\end{tabular}

\subsection{Beckmann Thermometers}

A metastatic, or Beckmann thermometer, usually of the enclosed-scale type, is constructed in a manner that permits mercury to be removed from, or added to, the bulb, making it possible to use the same thermometer for differential temperature measurements in various temperature ranges [11]. The scale usually consists of 5 or 6 Celsius degrees, although some micro types have a scale containing only 3 Celsius degrees. 
The "setting" of a Beckmann thermometer refers to the temperature of the bulb when the reading on the scale is $0^{\circ}$. When the setting is changed, enabling the thermometer to be used at a higher or lower tem. perature range, the quantity of mercury affected by a temperature change is not the same. Therefore, two equal changes in temperature at different settings cause different indications on the scale, and a "setting factor" must always be used to convert reading differences into actual temperature differences whenever the thermometer is used at any setting other than the one at which the scale was calibrated. These setting factors combine corrections for the different quantities of mercury during equal temperature changes, and the difference between the mercury-in-glass scale and the International Practical Temperature Scale of 1968. Table 11 lists setting factors calculated for thermometers of Jena $16^{111} 2$ glass or, its American equivalent, Corning normal. The scale calibrations for Beckmann thermometers as reported by NBS are applicable for a setting of $20^{\circ} \mathrm{C}$. Consequently, the

TABLE 11. - Setting factors for Beckmann thermometers

\begin{tabular}{c|c|c|c}
\hline \hline Setting & Factor & Setting & Factor \\
\hline $0{ }^{\circ} \mathrm{C}$ & 0.9935 & $55^{\circ} \mathrm{C}$ & 1.0092 \\
5 & 0.9951 & 60 & 1.0102 \\
10 & 0.9967 & 65 & 1.0112 \\
15 & 0.9984 & 70 & 1.0121 \\
20 & 1.0000 & 75 & 1.0129 \\
25 & 1.0014 & 80 & 1.0137 \\
30 & 1.0029 & 85 & 1.0146 \\
35 & 1.0042 & 90 & 1.0154 \\
40 & 1.0056 & 95 & 1.0162 \\
45 & 1.0070 & 100 & 1.0170 \\
50 & 1.0082 & & \\
\hline
\end{tabular}

As an illustration, suppose the following observations were made: Setting $=25^{\circ} \mathrm{C}$. $\quad$ Lower reading $=2.058^{\circ}$

Stem temperature $=24^{\circ} \mathrm{C} . \quad$ Upper reading $=5.127^{\circ}$

Lower Upper

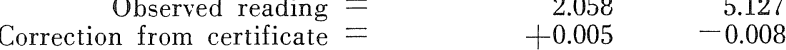

Corrected upper reading $\quad 5.119$

Corrected lower reading $\quad 2.063$

$\begin{aligned} \text { Difference } & =3.056 \\ \text { Difference multiplied by setting factor (1.0014) } & =3.060\end{aligned}$

Emergent stem correction (see accompanying

stem correction sheet) $=+.004$

Corrected difference $=+.004$

${ }^{2}$ Certain commercial products and instruments are identified in this paper in order to specify adequately the experimental procedure. In no case does in Bureau of Standards, nor does it imply that the products or equipment identified are necessarily the best available for the purpose. setting factor is 1.0000 at this temperature. For a setting other than $20^{\circ} \mathrm{C}$, the observed temperature difference must be multiplied by the appropriate setting factor as shown in the example given below the table.

For most Beckmann thermometers, the large bulb is joined to a fine capillary, which is backed by a milk-glass scale, by a capillary of much larger diameter. This large capillary is a source of some uncertainty when the thermometer is used at partial immersion and this portion is not entirely immersed. For appropriate emergent-stem corrections refer to section $5.3 \mathrm{e}$.

Tolerance requirements for Beckmann thermometers are given in table 12. Under the heading "Accuracy of interval in degrees" is given the estimated accuracy attainable in the measurement of any interval within the limits of the scale. No tolerances for scale error are given, although it is desirable that it be no larger than $0.02{ }^{\circ} \mathrm{C}$ over a $1.0{ }^{\circ} \mathrm{C}$ interval.

TABle 12. - Tolerances for Beckmann and calorimetric thermometers

\begin{tabular}{|c|c|c|c|}
\hline $\begin{array}{c}\text { Type of } \\
\text { thermometer }\end{array}$ & $\begin{array}{l}\text { Gradua- } \\
\text { tion in- } \\
\text { terval in } \\
\text { degrees }\end{array}$ & $\begin{array}{c}\text { Allowable change } \\
\text { in correction in } \\
\text { degrees }\end{array}$ & $\begin{array}{l}\text { Accuracy of } \\
\text { interval in } \\
\text { degrees }\end{array}$ \\
\hline Beckmann & $0.01{ }^{\circ} \mathrm{C}$ & $\begin{array}{l}0.01 \text { over } 0.5^{\circ} \\
\text { interval for } \\
\text { setting of } 20^{\circ} \mathrm{C}\end{array}$ & 0.002 to 0.005 \\
\hline Bomb calorimetric & $.01{ }^{\circ} \mathrm{C}$ & 0.02 over $1.5^{\circ}$ & .005 to .01 \\
\hline Do . & $.02{ }^{\circ} \mathrm{C}$ & $\begin{array}{l}0.02 \text { over } 1.5^{\circ} \\
\text { interval }\end{array}$ & .005 to .01 \\
\hline Do & $.05^{\circ} \mathrm{F}$ & $\begin{array}{l}0.04 \text { over } 2.5^{\circ} \\
\text { interval }\end{array}$ & \\
\hline Gas calorimetric ... & $.1^{\circ} \mathrm{F}$ & $\begin{array}{l}0.15 \text { over a } 5^{\circ} \\
\text { interval }\end{array}$ & .02 to .05 \\
\hline
\end{tabular}

\subsection{Calorimetric Thermometers}

Calorimetric thermometers include a specialized group of solid-stem mercury-in-glass thermometers which are used for accurate differential measurements. Since the accuracy of these thermometers at any one temperature is of less importance than the accuracy of the temperature intervals, no reference point is required.

Table 12 gives the scale error required of some typical calorimetric thermometers. Like the Beckmann thermometer, no tolerances for scale error are given, but it is desirable that the scale corrections be no larger than approximately five graduation intervals. 


\section{Thermometer Design}

Reproducibility and accuracy of readings are influenced markedly by the design, choice of materials, and actual construction of the thermometer. The calibration laboratory personnel exercise judgment in deciding whether individual thermometers are likely to maintain a calibration; however, general recommendations for acceptable thermometer design and construction are given in the following sections.

\subsection{Materials of Construction}

While the cleanliness of the thermometer bulb, bore, and liquid filling have a pronounced effect upon the performance of a thermometer, equally important is the proper choice of the glass from which the thermometer is manufactured. The thermometer, and especially the bulb, must be made of glass suitable for use in the temperature range indicated on the stem. Some types of glasses commonly used in the manufacture of thermometer bulbs and reasonable upper temperature limits are estimated by Thompson [12] in table 13. Thompson's estimates are based upon the work of Liberatore and Whitcome [13]. The results show that significant changes in bulb volume may occur if the bulb is heated for long periods of time at temperatures higher than $130^{\circ} \mathrm{C}\left(234^{\circ} \mathrm{F}\right)$ below the strain point of the bulb glass. The strain point of a glass is defined as the temperature at which the glass has a viscosity of $10^{14.5}$ poises [14]. Thermometers may be used intermittently, to approximately $70^{\circ} \mathrm{C}$ $\left(126^{\circ} \mathrm{F}\right)$ of the strain point. It should be noted that the use of a glass with a high strain point, such as borosilicate glass, results in better thermometer performance and stability even in thermometers used at temperatures much lower than the exposure limits given in table 13.

TABLE 13. - Temperature exposure limits for various thermometer glasses a

\begin{tabular}{|c|c|c|c|c|c|}
\hline & \multirow{2}{*}{$\begin{array}{c}\text { Strain } \\
\text { point }\end{array}$} & \multicolumn{4}{|c|}{ Exposure limits } \\
\hline & & \multicolumn{2}{|c|}{ Continuous } & \multicolumn{2}{|c|}{ Intermittent } \\
\hline & ${ }^{\circ} \mathrm{C}$ & ${ }^{\circ} \mathrm{C}$ & ${ }^{\circ} \mathrm{F}$ & ${ }^{\circ} \mathrm{C}$ & ${ }^{\circ} \mathrm{F}$ \\
\hline Corning normal $7560 \ldots$ & 500 & 370 & 700 & b430* & b805* \\
\hline Kimble R 6 & 490 & 360 & 680 & 420 & 790 \\
\hline Jena 16 III & 495 & 365 & 690 & 425 & 795 \\
\hline Corning borosilicate 8800 & 529 & 400 & 750 & 460 & 860 \\
\hline Jena borosilicate 2954 & 548 & 420 & 790 & 480 & 900 \\
\hline Corning 1720 & 668 & 540 & 1005 & 600 & 1110 \\
\hline Jena Supremax 2955 & 665 & 535 & 995 & 595 & 1100 \\
\hline
\end{tabular}

a From reference [12].

b $* 405^{\circ} \mathrm{C}$ or $760{ }^{\circ} \mathrm{F}$ if Corning Standard Thermometer 0041 glass is used for the stem.

The thermometer must also be adequately annealed to enable the bulb volume to remain reasonably stable and causing only small changes in the thermometer readings with continued use. This is especially important for a thermometer graduated above $300{ }^{\circ} \mathrm{C}$ or $600{ }^{\circ} \mathrm{F}$. The quality of the thermometer glass and the adequacy of the annealing process may be judged by the stability of the reference-point readings. A method for testing bulb stability is described in The American Society for Testing and Materials Method E77.

All high-temperature thermometers should be filled with a dry inert gas such as nitrogen under sufficient pressure to prevent separation of the mercury at any temperature indicated on the scale. Total-immersion thermometers graduated above $150^{\circ} \mathrm{C}$ or $300^{\circ} \mathrm{F}$ must be gas filled to minimize the distillation of mercury from the top of the mercury column. An expansion chamber at the top of the capillary or a specified length of unchanged capillary above the highest graduation is essential for thermometers containing a gas. The gas must have an adequate area for compression when the mercury is advanced toward the top of the scale; otherwise, excessive pressure in the capillary will cause the thermometer to burst.

For thermometers graduated below $150{ }^{\circ} \mathrm{C}$ or $300^{\circ} \mathrm{F}$ a gas filling is optional, but is strongly recommended. The mercury column of a vacuous thermometer will tend to separate easily if the thermometer is inverted or subjected to a sudden shock.

\subsection{Scalle Design and Workmanship}

Solid-stem thermometers must have the graduation marks placed directly on the stem and opposite the enamel back. If the thermometer is of the enclosedscale type, the graduated scale must be securely fastened to prevent relative displacement between the scale and the capillary, or a datum line should be conveniently located to indicate at any time whether the scale is in its original position. The graduation marks should be clear cut, straight, of uniform width, and in a plane perpendicular to the axis of the thermometer.

The scale should be graduated in $1.0,0.5,0.2$, or 0.1 degree intervals, or in decimal multiples. The divisions should be numbered in such a manner that the iden. tification of any graduation is not unnecessarily difficult. Thermometers with scales graduated in 0.25 degree intervals, or submultiples, are sometimes difficult to read and the discontinuance of their production is desirable. If the thermometers are graduated in 0.1 or 0.2 degree intervals (or decimal multiples), every fifth mark should be longer than the intermediate ones and a number should appear at every tenth mark. Thermometers graduated in 0.5 degree intervals (or decimal multiples) require three lengths of graduation marks. These consist of alternating short and intermediate marks, with every tenth line distinctly longer than the others. A number should appear at every 10 th or 20 th mark. 
The scale must not be extended to temperatures beyond which the particular thermometer glass is suited. A thermometer made of borosilicate glass, for example, should never be graduated to $500{ }^{\circ} \mathrm{C}$ $\left(932^{\circ} \mathrm{F}\right)$. It would be ruined in a short time if used at that temperature.

\subsection{Scale Dimensions}

Although optimum line width depends in some measure upon the intended use of a particular thermometer, coarse graduation marks do not represent good design. If the thermometer indications are to be observed precisely (for example to 0.1 of a division), the width of the graduation marks should not exceed 0.2 of the interval between the center lines of the graduations. In instances where the thermometer must be read quickly or in poor light, and less precision is expected, somewhat wider lines may be acceptable.

The graduation marks must not be too closely spaced. The closest permissible spacing depends upon the fineness and clearness of the marks. In no case should the distance between center lines of adjacent graduation marks on a solid-stem thermometer be less than $0.4 \mathrm{~mm}$. The minimum permissible interval between graduation marks for an enclosed-scale thermometer is $0.3 \mathrm{~mm}$ if the lines are ruled on a milkglass scale; otherwise, the minimum is also $0.4 \mathrm{~mm}$. The minimum in no case represents good design, and well-designed thermometers will have graduation intervals considerably larger than the specified minimum.

In order for a thermometer to be usable over the entire range of the scale, the graduation marks must not be placed too close to any enlargement in the capillary. Appreciable errors may result if any of the following conditions exist. (1) There is insufficient immersion of the mercury in the main bulb or a capillary enlargement; (2) the graduation marks have been placed over parts of the capillary that have been changed by manufacturing operations; or (3) the graduations are so close to the top of the thermometer that excessive gas pressure results when the mercury is raised to this level. The distances given below are considered as minimum limits commensurate with good thermometer design:

(a) A $13 \mathrm{~mm}$ length of unchanged capillary between the bulb and the lowest graduation, if the graduation is not above $100{ }^{\circ} \mathrm{C}\left(212^{\circ} \mathrm{F}\right)$; a $30 \mathrm{~mm}$ length if the graduation is above $100^{\circ} \mathrm{C}\left(212^{\circ} \mathrm{F}\right)$.

(b) A $5 \mathrm{~mm}$ length of unchanged capillary between an enlargement and the graduation next below, except at the top of the thermometer.

(c) A $10 \mathrm{~mm}$ length of unchanged capillary between an enlargement, other than the bulb, and the graduation next above, if the graduation is not above $100^{\circ} \mathrm{C}\left(212^{\circ} \mathrm{F}\right)$; a $30 \mathrm{~mm}$ length if the graduation is above $100^{\circ} \mathrm{C}\left(212^{\circ} \mathrm{F}\right)$.

(d) A $10 \mathrm{~mm}$ length of unchanged capillary above the highest graduation, if there is an expansion chamber (see definitions, Sec. 3); a $30 \mathrm{~mm}$ length if there is no expansion chamber.

\subsection{Reference Point}

Thermometers graduated above $150^{\circ} \mathrm{C}$ or $300^{\circ} \mathrm{F}$, or precision thermometers with an expected accuracy of better than $0.1{ }^{\circ} \mathrm{C}$ or $0.2^{\circ} \mathrm{F}$ when calibrated for actual temperature measurement, must have a reference point. The effects of changes in the bulb volume on the thermometer indications may be followed throughout the life of the thermometer by periodic testing at the reference point. From the reference point observations, the thermometer corrections can be kept current as explained in section 5.2. If a suitable reference point, such as the ice or steam point, is not included in the range of the main scale, a short auxiliary scale containing a fixed point should be provided. To prevent the thermometer from being unduly long, a contraction chamber may be introduced between the auxiliary scale and the main scale. Any auxiliary scale must have graduations identical to those on the main scale, both dimensionally and in terms of temperature, and they must extend for a short interval both above and below the reference point. Similarly, when the main scale ends near a reference point, the graduations must be continued for a short interval beyond the reference temperature.

Reference points are not needed on thermometers intended for differential measurements (such as calorimetric thermometers), nor on thermometers graduated below $150{ }^{\circ} \mathrm{C}$ or $300^{\circ} \mathrm{F}$, if they are not to be calibrated to an accuracy of better than $0.1^{\circ} \mathrm{C}$ or $0.2^{\circ} \mathrm{F}$.

\subsection{Marking of Partial-Immersion Thermometers}

Partial-immersion thermometers must be plainly marked "partial immersion" or the equivalent (for example, "76 mm immersion"), or a conspicuous line permanently placed on the stem to indicate the proper depth of immersion. This line must not be less than $13 \mathrm{~mm}$ above the top of the bulb. Special partialimmersion thermometers, made for use in a specific manner or instrument (for example, viscometers and flash-point testers where the thermometer is held in a ferrule or other mounting arrangement suited to the instrument), need not be marked. 


\section{Special Notes}

The following brief notes on the characteristic behavior of mercury-in-glass thermometers are added to aid the user in understanding the behavior of these thermometers, and to better utilize the information contained in the Reports of Calibration.

\subsection{Glass Changes}

The changes which occur in the glass of a thermometer bulb after first heating to a high temperature within the acceptable exposure limits of the glass and subsequent cooling to ambient temperatures, are an involved function of time and temperature. They will depend upon the thermal history of the glass (both during manufacture and previous use), the time of exposure to the high temperature, and the rate of cooling. Evidence from many investigations $[13,15$, 16] seems to indicate that when a glass is held indefinitely at some fixed temperature, density (and volume) changes proceed toward a preferred density corresponding to a quasi equilibrium condition characteristic of the particular kind of glass and the temperature. Since these changes involve molecular rearrangements, they proceed more rapidly at high temperatures where the viscosity of the glass is lower, and the molecular mobility consequently higher. For this reason, a close approach to quasi equilibrium may be reached in the order of hours at annealing temperatures, while infinite time may be required at much lower temperatures.

If a glass that has been heated to a high temperature is allowed to cool rapidly, it will be seen that equilibrium is not reached at the lower temperatures during cooling, and an equilibrium density more nearly corresponding to the high temperature is "frozen" into the glass. This characteristic behavior of glass has a lasting effect on the performance of liquid-in-glass thermometers. For the entire lifetime of the thermometer it may retain a "memory" of the thermal history at the higher temperatures.

The techniques of good manufacture are designed to produce in the thermometer glass a state which will result in maximum stability for the range of temperature indicated on the scale. To achieve perfect stability for all conditions of use is not possible in thermometer manufacture; therefore, changes in the ice-point readings are observed periodically. The changes observed at the ice point are reflected at all points on the scale by the same magnitude and sign, since they are the result of changes in the bulb volume (see Sec. 5.2) (changes in the stem have very little effect). Because of this behavior of glass, the changes in the bulb volume can be either temporary or permanent.

\section{a. Temporary Changes}

Upon heating to a high temperature, the bulb of a thermometer will expand from its initial state. After a short period of time, an equilibrium condition cor- responding to that particular high temperature will appear to be reached. If the thermometer is cooled slowly through critical temperature regions, the glass will nearly return to its initial state, and the icepoint reading will show no change. If, on the other hand, the thermometer is cooled rapidly (such as cooling naturally in still air), the bulb will retain a portion of its expanded condition, and the ice-point reading will be lower than the reading taken before heating. This phenomenon is known as "zero, or icepoint depression." Thermometers which have been heated to high temperatures recover from this icepoint depression in an unpredictable way, and frequently there will be no significant recovery after a period of one year at room temperature. Since the ice-point depression has a reproducible value, icepoint readings may be used reliably to show changes in the volume of the thermometer bulb with time and use, provided the thermometer is allowed to cool in still air and the ice point is taken within a reasonable period of time, not to exceed one hour, after being heated.

Thermometers used below approximately $100{ }^{\circ} \mathrm{C}$ will usually exhibit a relatively rapid recovery from the ice-point depression, and the original bulb volume will recover within the equivalent of 0.01 or 0.02 degrees $\mathrm{C}$ in approximately 3 days. This phenomenon has an important bearing on the precision attainable with mercury thermometers, and must be taken into consideration, especially in the range of 0 to $100^{\circ} \mathrm{C}$. If a thermometer is used to measure a given temperature, it will indicate an erroneously low value if it has, within a short period of time, previously been exposed to a higher temperature. With the better grades of thermometric glasses the error resulting from this hysteresis will not exceed (in the interval of 0 to $100{ }^{\circ} \mathrm{C}$ ) 0.01 of a degree for each 10-degree difference between the temperature being measured and the higher temperature to which the thermometer has recently been exposed. With the best glasses the error may only be a few thousandths of a degree for each 10-degree difference. The errors due to this hysteresis become somewhat erratic at temperatures above $100{ }^{\circ} \mathrm{C}$. For these reasons it is customary, in precision thermometry, to apply a scale correction based upon an ice-point reading taken immediately after the temperature measurement (see Sec. 5.2).

Where the range of temperature is small and the time between observations is short (as in the use of calorimetric thermometers), it is more satisfactory, each time the thermometer is used, to first heat to the highest temperature to be measured, so that all of the depression has taken place before the observations are begun. The condition to be observed is that the time required for observations is so short that no appreciable recovery shall have taken place during this time. As this condition is fairly well satisfied in calorimetric work, and as it is the only one for which 
consistent measurements of the same temperature interval can be made repeatedly, calorimetric thermometers should be used in this way.

\section{b. Permanent Changes}

A "secular change" in thermometer glasses, which may progress with time, results in a non-recoverable decrease in the bulb volume as indicated by an increase in the ice-point reading. At room temperature there may be a gradual change which will continue for years, but at high temperatures the changes will be markedly accelerated. With better grades of thermometer glasses the change will not exceed $0.1^{\circ} \mathrm{C}$ over a period of many years, provided the thermometer has not been heated to temperatures above approximately $150^{\circ} \mathrm{C}$. Initially, at high temperatures, the secular change usually progresses more rapidly, but with continued heating and time it tends toward a lower rate of change. The rate of secular change will depend upon the kind of glass used in the thermometer bulb and the particular heat treatment given the thermometer in manufacture. Thermometers manufactured according to good practices will evidence only small secular changes. However, thermometers made of glass unsuitable for the temperature range indicated on the scale, or improperly annealed, may show changes as large as $12^{\circ} \mathrm{C}$ or $21^{\circ} \mathrm{F}$ after heating for approximately 200 hours at high temperatures [17]. Permanent changes in the bulb volume have also been observed when thermometers have been repeatedly cycled at low temperatures (between -30 and $+25^{\circ} \mathrm{C}$ ) [18].

When using thermometers for high temperature measurements, one must use care to avoid overheating. After only a few minutes of heating the thermometer at a temperature higher than its intended range, the increased gas pressure above the liquid column may cause a permanent distortion of the bulb resulting in lower thermometer indications.

\subsection{Pressure Effects}

Since glass exhibits elastic properties, the volume of a thermometer bulb will change when either the internal or external pressure changes. Therefore, at a given temperature, the reading of a thermometer in a horizontal position will differ from the reading in a vertical position. Thermometer readings will also vary with altitude. Changes of approximately $0.1{ }^{\circ} \mathrm{C}$ $\left(0.2^{\circ} \mathrm{F}\right)$ per atmosphere have been observed for many thermometers with bulb diameters between 5 and $7 \mathrm{~mm}$. This value can be used with some confidence for estimating the probable effect of an external pressure change. The effect of change of internal pressure is approximately 10 percent greater.

Formulas for both external and internal pressure coefficients have been derived by Guillaume [19]. He found the relation,

$$
\beta_{\mathrm{e}}=k \frac{\mathrm{R}_{\mathrm{e}}{ }^{2}}{\mathrm{R}_{\mathrm{e}}{ }^{2}-\mathrm{R}_{\mathrm{i}}{ }^{2}}
$$

where $R_{\mathrm{e}}$ and $R_{\mathrm{i}}$ are external and internal radii of the bulb, and $k$ is a constant containing elastic properties of the glass and a conversion factor for expressing the volume change in terms of change of thermometer reading in degrees. In the above formula, the external pressure coefficient $\beta$ is defined as the change in scale reading in degrees resulting from a change of $1 \mathrm{~mm} \mathrm{Hg}$ in external pressure. For Celsius thermometers, Guillaume found a value of $5.2 \times 10^{-5}$ degrees $\mathrm{C} / \mathrm{mm} \mathrm{Hg}$ for $k$, but Hall and Leaver [10], by experiment, found a value approximately 25 percent lower for their thermometers. In cases where an accurate correction is necessary, the value, $\beta_{\mathrm{e}}$, should be determined experimentally. A simple apparatus for this determination is shown in figure 9 .

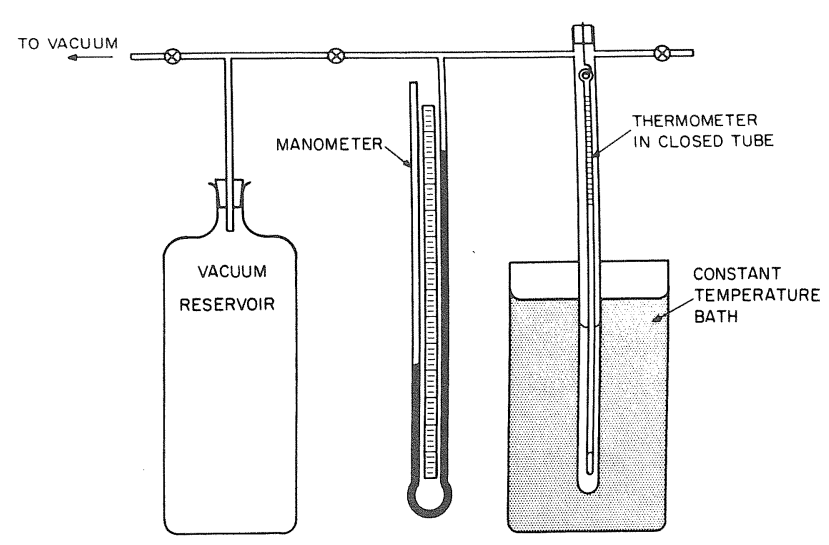

Figure 9. Apparatus for measurement of the external pressure coefficient.

The internal pressure coefficient, $\beta_{\mathrm{i}}$, is more difficult to determine accurately, but may be calculated from the value, $\beta_{\mathrm{e}}$, by means of the relation,

$$
\beta_{\mathrm{i}}=\beta_{\mathrm{e}}+1.5 \times 10^{-5}
$$

for thermometers in Celsius degrees, or

$$
\beta_{\mathrm{i}}=\beta_{\mathrm{e}}+2.7 \times 10^{-5}
$$

for thermometers graduated in Fahrenheit degrees.

\subsection{Lag}

Practically all theoretical treatments concerning thermometer lag are based on the assumption that Newton's law of cooling is applicable (that the rate of change in the reading of the thermometer is proportional to the difference between the thermometer temperature and the bath temperature). Consequently, when a thermometer is immersed in any medium, it does not indicate the temperature immediately, but approaches it asymptotically. A detailed discussion of this subject has been given by Harper [20].

If the temperature of the medium is varying uniformly, the thermometer always indicates what the temperature was at some previous time. The thermom- 
eter readings are said to "lag" behind the temperature of the medium by an amount which may or may not be negligible, depending upon the rapidity of the temperature variation and the physical characteristics of the thermometer. In this case, the lag, $\lambda$, may be defined as the interval in seconds between the time when the bath reaches a given temperature and the time when the thermometer indicates that temperature. This lag is dependent upon the dimensions and material of the thermometer bulb, the medium surrounding the thermometer and the stirring rate of the medium. If a thermometer is suspended in still air, the lag may be as much as 50 times that of the same thermometer when it is immersed in a well-stirred water bath. Since the value of the lag for mercurial thermometers is not large (from 2 to 10 seconds in a well-stirred water bath), it is not generally necessary to correct for it. For example, if two thermometers, one having a lag of 3 seconds and another of 8 seconds, are read simultaneously in a bath with the temperature rising at a rate of 0.001 degree in 5 seconds, the former will read 0.001 degree higher than the latter, due to the lag. In the intercomparison of thermometers, the rate of temperature rise can usually be kept small, making the lag correction negligible.

A second interpretation of thermometer lag involves immersing a thermometer in a bath where the temperature of the medium remains constant. A certain time must elapse before the thermometer reading agrees with the temperature of the medium to 0.1 of a degree, and still longer for agreement to be within 0.01 of a degree. In this case the lag, $\lambda$, is the time required for the original difference in temperature between the thermometer and bath medium to be reduced to $1 / \mathrm{e}$ (that is $1 / 2.7$ ) of itself. In a length of time $4 \lambda$ the difference will be approximately 1.5 percent of the original difference, and in a length of time $7 \lambda$ approximately 0.1 percent. Determinations of $\lambda$ for solid-stem laboratory thermometers, representative of American manufacture, have yielded values of approximately 2 to 3 seconds in a well-stirred water bath. Figure 10 shows the approach of thermometer readings to the water bath temperature for three selected thermometers having different values of $\lambda$. If the thermometer having $\lambda=2.2$ seconds is initially at $25^{\circ} \mathrm{C}$. and is immersed in a constant temperature bath at $75{ }^{\circ} \mathrm{C}$, the thermometer reading will be within $0.05{ }^{\circ} \mathrm{C}\left(0.1\right.$ percent of $\left.50{ }^{\circ} \mathrm{C}\right)$ of the bath temperature in 15 seconds, and within $0.01{ }^{\circ} \mathrm{C}$ in 19 seconds. The curve showing $\lambda=3.1$ was obtained for an American Society for Testing and Materials (ASTM) specification $56 \mathrm{C}$ calorimetric thermometer with an outside bulb diameter of $7.9 \mathrm{~mm}$ and a bulb length of $44 \mathrm{~mm}$. The value of $\lambda=2.2$ was found for an ASTM 7C thermometer having bulb dimensions of 5.4 by $12 \mathrm{~mm}$. The third curve, where $\lambda=1.7$, was obtained for a bulb with dimensions of 5.4 by $34 \mathrm{~mm}$. It is probable that most solid-stem thermometers of American manufacture will have values of $\lambda$ lying within the range of the three curves shown. It will be noted that, according to Harper [20], the value

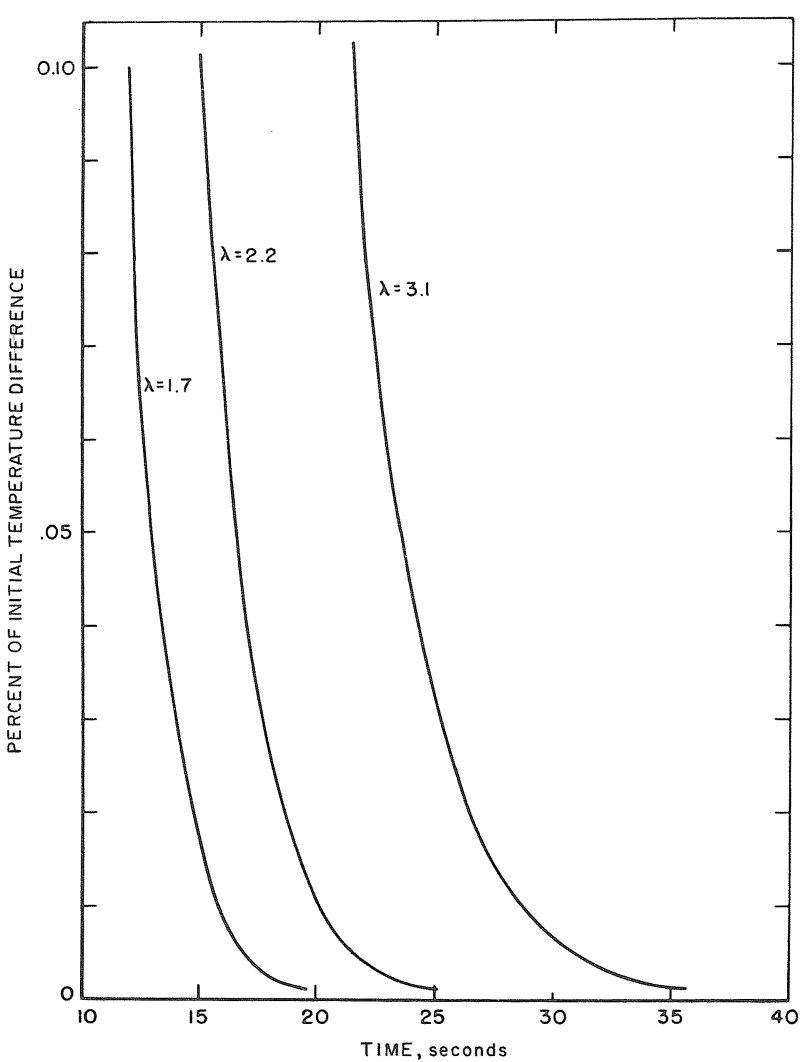

Figure 10. The approach to temperature in a stirred water bath for three thermometers with typical lag constants.

of $\lambda$ for a given thermometer in a well stirred oil bath will be approximately twice its value in a water bath.

For a thermometer which is used to measure temperature changes (as in calorimetry), it has been shown by White [21] that the lag enters into the observations in such a way as to be eliminated from the results in applying the usual radiation corrections. Therefore the lag need not be considered, providing the initial and final readings are made when the temperature is varying uniformly. This is not strictly true, however, in the case of some Beckmann thermometers, which have no true value of $\lambda$, as is ex. plained in the paper referred to above.

\subsection{Separated Columns}

Many inquiries are received concerning separated mercury columns which occur especially during shipment. Since no means of avoiding such occurrences has yet been found, some directions for joining the mercury may be helpful and are described below.

(a) The bulb of the thermometer may be cooled in a solution of common salt, ice, and water (or other cooling agent) to bring the mercury down slowly into the bulb. If the salt solution does not provide sufficient cooling, carbon dioxide snow (dry ice) may be used. Since the temperature of dry ice is approximately 
$-78{ }^{\circ} \mathrm{C}\left(-108{ }^{\circ} \mathrm{F}\right)$, and mercury freezes at approximately $-40^{\circ} \mathrm{C}\left(-40^{\circ} \mathrm{F}\right)$, the mercury will solidify. Cool only the bulb and never the stem or mercury column. Moderate tapping of the bulb on a rubber stopper or similar soft spongy object, or the application of centrifugal force, by swinging the thermometer in a short arc (i.e. use of centrifugal force), usually serves to unite the mercury in the bulb. Care must be taken to warm the top of the bulb first, so that pressures in the bulb due to expanding mercury may be relieved.

(b) If there is a contraction chamber above the bulb or an expansion chamber at the top of the thermometer, the mercury can sometimes be united by warming the bulb until the column reaches the separated portions in either enlargement. Great care is necessary to avoid filling the expansion chamber completely with mercury, which might produce pressures large enough to burst the bulb. (The expansion chamber should never be more than $2 / 3$ full.) Joining the mercury is more readily accomplished if the quantity in either cavity has first been shattered into droplets by tapping the thermometer laterally against the hand.

This procedure should not be used if it requires the thermometer to be heated above $260{ }^{\circ} \mathrm{C}\left(500{ }^{\circ} \mathrm{F}\right)$ and the bulb should never be heated in an open flame.

(c) As a last resort, especially for thermometers having no expansion chambers, small separated portions of the column can sometimes be dispersed by warming into droplets tiny enough to leave space for the gas to by-pass. The thermometer is heated, and the droplets are collected by the rising mercury column.

The procedure for thermometers containing organic liquids is similar. Separated liquid in the stem can be vaporized and permitted to drain down the capillary. Another method consists of gently tapping the stem above the separation against the palm of the hand, forcing the organic liquid to break away from the wall of the capillary and flow down the bore to join the main column.

Minute gas bubbles, which are sometimes found along the surface of the mercury in the thermometer bulb, may be collected by "washing" the bulb with a large gas bubble. Bring all of the mercury into the bulb as outlined in section (a). Hold the thermometer in a horizontal position and gently tap it against the hand to form a large gas bubble. Force the bubble to travel around the walls of the bulb by rotating the thermometer and tapping it against the palm of the hand. When the entire surface has been "washed" rotate the bubble to the top of the bulb and reunite the mercury as described above.

All of these manipulations require patience, and experience is helpful, but they will yield results if care is used. A convenient method of ascertaining that all of the liquid has been joined is a check of the ice point or some other reference point on the scale.

\section{References}

[1] "The International Practical Temperature Scale of 1968," Metrologia, Vol. 5, No. 2, 35 (April, 1969).

[2] Calibration and Test Services of The National Bureau of Standards, NBS Spec. Publ. 250 (1970 Edition), Part 5. (Copies available from NBS on request).

[3] Comptes Rendus des Séances de la Treizième Conférence Générale des Poids et Mesures (1967-1968), Resolutions 3 and 4, p. 104.

[4] Stimson, H. F., The International Practical Temperature Scale of 1948, J. Res. Nat. Bur. Stand. (U.S.), 65A (Phys. and Chem.), No. 3, 139-145 (May-June 1961).

[5] Based on the data of Osborne, N. S., and Meyers, C. H. A formula and tables for the pressure of saturated water vapor in the range 0 to $374{ }^{\circ} \mathrm{C}$, J. Res. NBS 13 , 1 (1934) RP691.

[6] Scott, R. B., and Brickwedde, F. G., A precision cryostat with automatic temperature regulation, BS J. Res. 6 , 401 (1931) RP284.

[7] American Society for Testing and Materials Designation E77-72, Calibration at Temperatures Other Than Fixed Points, Section 11.2.

[8] Buckingham, E., The correction for emergent stem of the mercurial thermometer, Bul. BS 8, 239 (1912) S170.

[9] Pemberton, L. H., Further consideration of emergent column correction in mercury thermometry, J. Sci. Instr. 41, 234 (1964).

[10] Hall, J. A., and Leaver, V. M., The design of mercury thermometers for calorimetry, J. Sci. Instr. 36, 183 (1959).
[11] Ween, Sidney, "The Beckmann Differential Thermometer: Its Principles of Construction and Application," Materials Research and Standards, MTRSA, Vol. 12, No. 8, August 1972, p. 31.

[12] Thompson, R. D., Recent developments in liquid-in-glass thermometry, Temperature, Its Measurement and Control in Science and Industry 3, Part 1 (Reinhold Publishing Corp., New York, 1962) p. 201.

[13] Liberatore, L. C., and Whitcomb, H. J., Density changes in thermometer glasses, J. Am. Ceram. Soc. 35, 67 (1952).

[14] American Society for Testing and Materials Designation C162-56, Standard Definitions of Terms Relating to Glass and Glass Products.

[15] Lillie, H. R., and Shaver, W. W., Method of tempering glass, U.S. Patent No. 2,148,630 (Feb. 28, 1939).

[16] Liberatore, L. C., Method of stabilizing the molecular arrangement of glass thermometers, U.S. Patent No. 2,610,445 (Sept. 16, 1952).

[17] Ruh, E. L., and Conklin, G. E., Thermal stability in ASTM thermometers, ASTM Bul. No. 233, 35 (Oct. 1958) .

[18] Martin, W. I., and Grossman, S. S., Calibration drift with thermometers repeatedly cooled to $-30^{\circ} \mathrm{C}$, ASTM Bul. No. 231, 62 (July 1958).

[19] Guillaume, C. E., Traité Practique de la Thermométrie, Gauthier-Villars et Fils, Paris (1889) p. 99.

[20] Harper 3d, D. R., Thermometric lag, Bul. BS 8, 659 (1912) S185.

[21] White, W. P., Lag effects and other errors in calorimetry, Phys. Rev. 31, 562 (1910). 
NBS-114A (REV. 7-73)

\begin{tabular}{|c|c|c|c|}
\hline $\begin{array}{l}\text { U.S. DEPT. OF COMM. } \\
\text { BIBLIOGRAPHIC DATA } \\
\text { SHEET }\end{array}$ & $\begin{array}{l}\text { 1. PUBLICATION OR REPORT NO. } \\
\text { NBS Monogr. } 150\end{array}$ & $\begin{array}{l}\text { 2. Gov't Accession } \\
\text { No. }\end{array}$ & 3. Recipient's Accession No. \\
\hline \multicolumn{3}{|l|}{ 4. TITLE AND SUBTITLE } & $\begin{array}{l}\text { 5. Publication Date } \\
\text { January } 1976\end{array}$ \\
\hline \multicolumn{2}{|c|}{ LIQUID-IN-GLASS THERMOMETRY } & \multicolumn{2}{|c|}{ NBS MONOGRAPH } \\
\hline \multicolumn{3}{|l|}{ 7. AUTHOR(S) } & 8. Performing Organ. Report No. \\
\hline \multicolumn{3}{|c|}{$\begin{array}{l}\text { NATIONAL BUREAU OF STANDARDS } \\
\text { DEPARTMENT OF COMMERCE } \\
\text { WASHINGTON, D.C. } 20234\end{array}$} & 10. Project/Task/Work Unit No. \\
\hline \multirow{2}{*}{\multicolumn{3}{|c|}{ 12. Sponsoring Organization Name and Complete Address (Street, City, State, ZIP) }} & $\begin{array}{l}\text { 13. Type of Report \& Period } \\
\text { Covered } \\
\text { Final }\end{array}$ \\
\hline & & & 14. Sponsoring Agency Code \\
\hline
\end{tabular}

15. SUPPLEMENTARY NOTES

Library of Congress Catalog Card Number: $75-619230$

16. ABSTRACT (A 200-word or less factual summary of most significant in formation. If document includes a significant bibliography or literature survey, mention it here.)

This Monograph, which supersedes NBS Monograph 90 , contains information of general interest to manufacturers and users of liquid-in-glass thermometers. Instructions explaining how to submit a thermometer to the National Bureau of Standards for calibration are provided, and the techniques and equipment, such as stirred liquid comparison baths, used in the calibration procedures are described. A discussion of important principles of acceptable thermometer design and factors affecting their use is included. Listed are tables of tolerances reflecting good manufacturing practices and reasonably attainable accuracies expected with liquid-in-glass thermometers. The calculation of corrections for the temperature of the emergent stem is given in detail for various types of thermometers and conditions of use.

17. KEY WORDS (six to twelve entries; alphabetical order; capitalize only the first letter of the first key word unless a proper name; separated by semicolons)

Calibration; emergent stem; 1iquid-in-glass thermometer; reference point; stirred liquid comparison bath; temperature scale.

\begin{tabular}{|c|c|c|}
\hline $\begin{array}{l}\text { 18. AVAILABILITY } \bar{X} \text { Unlimited } \\
\square \text { For Official Distribution. Do Not Release to NTIS }\end{array}$ & $\begin{array}{l}\text { 19. SECURITY CLASS } \\
\text { (THIS REPURT) } \\
\text { UNCL ASSIF IED }\end{array}$ & $\begin{array}{l}\text { 21. NO. OF PAGES } \\
30\end{array}$ \\
\hline $\begin{array}{l}{\left[\mathrm{X} \text { Order From Sup. of Doc., U.S. Government Prigting } 8^{\text {ffice }}\right.} \\
\text { Washington, D.C. } 20402, \text { SD Cat. No.C13.44:15 } \\
\square \text { Order From National Technical Information Service (NTIS) } \\
\text { Springfield, Virginia } 22151\end{array}$ & $\begin{array}{l}\text { 20. SECURITY CLASS } \\
\text { (THIS PAGE) } \\
\text { UNCLASSIFIED }\end{array}$ & $\begin{array}{l}\text { 22. Price } \\
85 \text { cents }\end{array}$ \\
\hline
\end{tabular}





\section{NBS TECHNICAL PUBLICATIONS}

\section{PERIODICALS}

JOURNAL OF RESEARCH reports National Bureau of Standards research and development in physics, mathematics, and chemistry. It is published in two sections, available separately:

\section{- Physics and Chemistry (Section A)}

Papers of interest primarily to scientists working in these fields. This section covers a broad range of physical and chemical research, with major emphasis on standards of physical measurement, fundamental constants, and properties of matter. Issued six times a year. Annual subscription: Domestic, \$17.00; Foreign, $\$ 21.25$.

\section{- Mathematical Sciences (Section B)}

Studies and compilations designed mainly for the mathematician and theoretical physicist. Topics in mathematical statistics, theory of experiment design, numerical analysis, theoretical physics and chemistry, logical design and programming of computers and computer systems. Short numerical tables. Issued quarterly. Annual subscription: Domestic, \$9.00; Foreign, \$11.25.

DIMENSIONS/NBS (formerly Technical News Bulletin)-This monthly magazine is published to inform scientists, engineers, businessmen, industry, teachers, students, and consumers of the latest advances in science and technology, with primary emphasis on the work at NBS. The magazine highlights and reviews such issues as energy research, fire protection, building technology, metric conversion, pollution abatement, health and safety, and consumer product performance. In addition, it reports the results of Bureau programs in measurement standards and techniques, properties of matter and materials, engineering standards and services, instrumentation, and automatic data processing.

Annual subscription: Domestic, \$9.45; Foreign, \$11.85.

\section{NONPERIODICALS}

Monographs-Major contributions to the technical literature on various subjects related to the Bureau's scientific and technical activities.

Handbooks-Recommended codes of engineering and industrial practice (including safety codes) developed in cooperation with interested industries, professional organizations, and regulatory bodies.

Special Publications-Include proceedings of conferences sponsored by NBS, NBS annual reports, and other special publications appropriate to this grouping such as wall charts, pocket cards, and bibliographies.

Applied Mathematics Series-Mathematical tables, manuals, and studies of special interest to physicists, engineers, chemists, biologists, mathematicians, computer programmers, and others engaged in scientific and technical work.

National Standard Reference Data Series-Provides quantitative data on the physical and chemical properties of materials, compiled from the world's literature and critically evaluated. Developed under a world-wide program coordinated by NBS. Program under authority of National Stradard Data A.ct (Public Law 90-396).

NOTE: At present the principal publication outlet for these data is the Journal of Physical and Chemical Reference Data (JPCRD) published quarterly for NBS by the American Chemical Society (ACS) and the American Institute of Physics (AIP). Subscriptions, reprints, and supplements available from ACS, 1155 Sixteenth St. N. W., Wash. D. C. 20056.

Building Science Series-Disseminates technical information developed at the Bureau on building materials, components, systems, and whole structures. The series presents research results, test methods, and performance criteria related to the structural and environmental functions and the durability and safety characteristics of building elements and systems.

Technical Notes-Studies or reports which are complete in themselves but restrictive in their treatment of a subject. Analogous to monographs but not so comprehensive in scope or definitive in treatment of the subject area. Often serve as a vehicle for final reports of work performed at NBS under the sponsorship of other government agencies.

Voluntary Product Standards-Developed under procedures published by the Department of Commerce in Part 10, Title 15, of the Code of Federal Regulations. The purpose of the standards is to establish nationally recognized requirements for products, and to provide all concerned interests with a basis for common understanding of the characteristics of the products. NBS administers this program as a supplement to the activities of the private sector standardizing organizations.

Federal Information Processing Standards Publications (FIPS PUBS)-Publications in this series collectively constitute the Federal Information Processing Standards Register. Register serves as the official source of information in the Federal Government regarding standards issued by NBS pursuant to the Federal Property and Administrative Services Act of 1949 as amended, Public Law 89-306 (79 Stat. 1127), and as implemented by Executive Order 11717 ( 38 FR 12315, dated May 11, 1973) and Part 6 of Title 15 CFR (Code of Federal Regulations).

Consumer Information Series-Practical information, based on NBS research and experience, covering areas of interest to the consumer. Easily understandable language and illustrations provide useful background knowledge for shopping in today's technological marketplace.

NBS Interagency Reports (NBSIR)-A special series of interim or final reports on work performed by NBS for outside sponsors (both government and non-government). In general, initial distribution is handled by the sponsor; public distribution is by the National Technical Information Service (Springfield, Va. 22161) in paper copy or microfiche form.

Order NBS publications (except NBSIR's and Bibliographic Subscription Services) from: Superintendent of Documents, Government Printing Office, Washington, D.C. 20402 .

\section{BIBLIOGRAPHIC SUBSCRIPTION SERVICES}

The following current-awareness and literature-survey bibliographies are issued periodically by the Bureau: Cryogenic Data Center Current Awareneas Service

A literature survey issued biweekly. Annual subscription: Domestic, \$20.00; foreign, $\$ 25.00$.

Liquefied Natural Gas. A literature, survey issued quarterly. Annual subscription: $\$ 20.00$.

Superconducting Devices and Materials. A literature survey issued quarterly. Annual subscription: $\$ 20.00$. Send subscription orders and remittances for the preceding bibliographic services to National Technical Information Service, Springfield, Va. 22161.

Electromagnetic Metrology Current Awareness Service Issued monthly. Annual subscription: \$24.00. Send subscription order and remittance to Electromagnetics Division, National Bureau of Standards, Boulder, Colo. 80302. 
U.S. DEPARTMENT OF COMMERCE

National Bureau of Standards

Washington, D.C. 20234

OFFICIAL BUSINESS

Penalty for Private Use, $\$ 300$
POSTAGE AND FEES PAID U.S. DEPARTMENT OF COMMERCE $C O M-295$

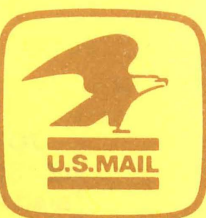

Fourth Class Mail 